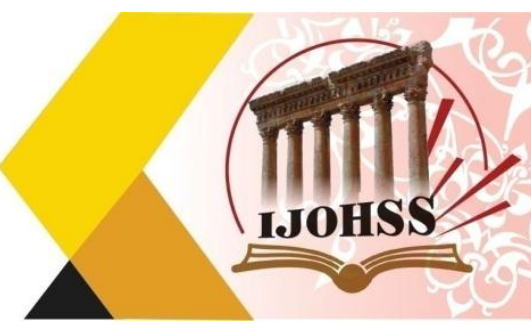

\title{
فلسفة هيجل في التاريخ 1770 - 1831م
}

\author{
الاكتورة آمنة محمود الأيابات

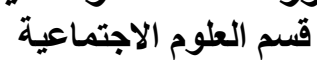 \\ كلية الآداب - جامعة الاجتماعئة حائل \\ حائل ـ المملكة العربية السعودية جائة \\ البريد الاككتروني: anadyabat@gmail.com
}

الماخص

يتناول البحث موضع فلسفة التاريخ عند احد كبار فلاسفة القرن التاسع عشر المفكر والفيلسوف الالماني هيغل جورج فليلهيلم فريدريك 1770 - 1831م.وقد تكون البحث من اربعة مباحث هي: بدأت في المقدمة/الملخص ثم المبحث الأول: بعنوان حياة هيغل ومؤلفاته وتناول المبحث الثناني: مصادر فلسفة هيغل ومنهجه الجدلي، واهتم المبحث الثنالث ب: - فلسفة التاريخ الهيغلية واختص المبحث الر ابع ب : فلسفة هيجل بين النقد والتقدير ثم النتائج وقائمة المر اجع العربية والاجنبية والمعربة التي اعتمدت عليها في البحث ، وخلص البحث الى النتائج التالية : رفض هيغل النظرية التطورية باعنبار التاريخ لا يعيد نفسه، ونشاط الأحداث التاريخية لا تأخذ شكلاً دائرياً ، إنما حركة ملتفة تصاعدية، والنشاط رغم تكراره إلا أنه مختلف عن سابقه. اتهم هيغل بتحريضه على الحرب ، وتثديده على القومية. لم يتطرق في مؤلفاته الى الحضارة الاسلامية. 


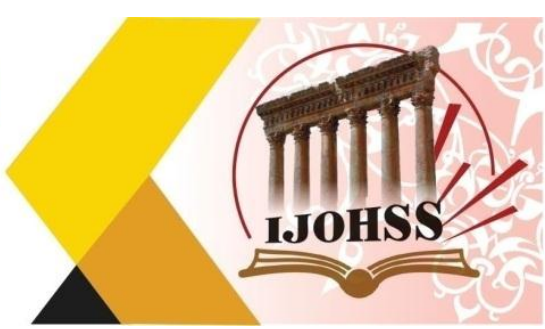

\title{
Hegel's Philosophy in History 1770-1831
}

\author{
Dr. Amnah Mahmoud Al-Thiabat \\ Department of Social Sciences \\ College of Arts \\ University of Hail \\ Hail - Kingdom of Saudi Arabia \\ Email: anadyabat@gmail.com
}

\begin{abstract}
The research deals with the subject of the philosophy of history of one of the leading philosophers of the nineteenth century, the German thinker and philosopher Hegel, George Wilhelm Friedrich, 1770-1831 A.D. The research may consist of four topics: it started in the introduction / abstract, then the first topic: titled Hegel's life and his works, and the second topic: Philosophy Sources Hegel and his dialectical approach, and the third topic was concerned with: - The philosophy of Hegelian history and the fourth topic is concerned with: Hegel's philosophy between criticism and appreciation, then the results and the list of Arab, foreign and Arabized references on which it relied In the research, the research concluded the following results: Hegel rejected the evolutionary theory as history does not repeat itself, and the activity of historical events does not take a circular shape, but rather an upward spiraling movement, and activity despite its repetition is different from its predecessor. Hegel was accused of instigating war and stressing nationalism. He did not mention in his books the Islamic civilization.
\end{abstract}

Keywords: History, Hegel, Hegel's philosophy, nineteenth century philosophers. 


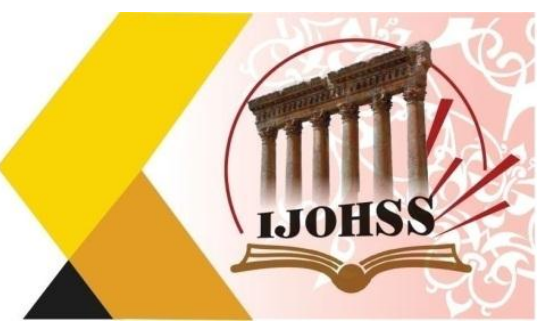

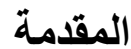

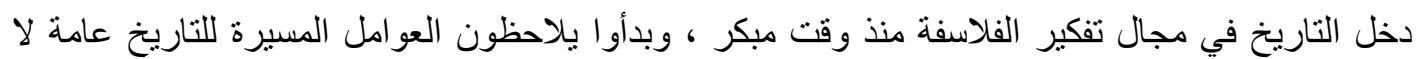

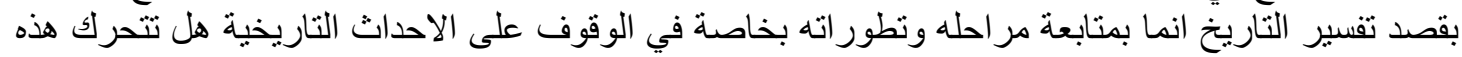

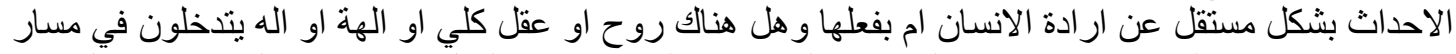

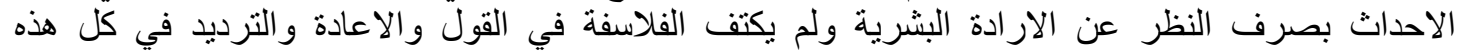

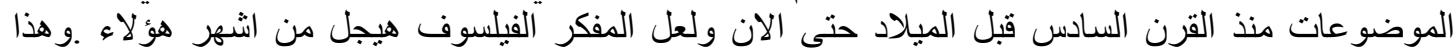

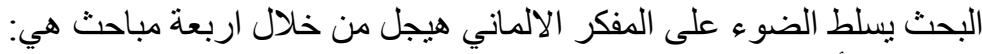

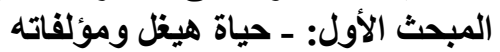

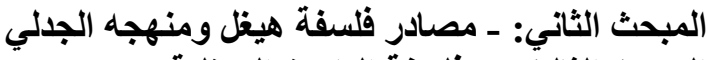

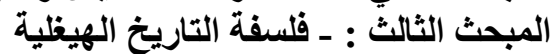

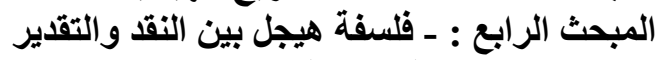

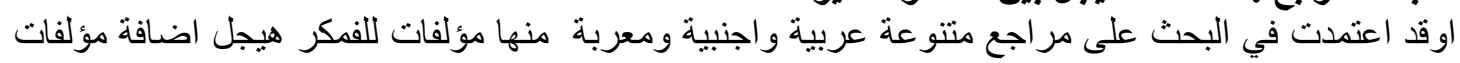

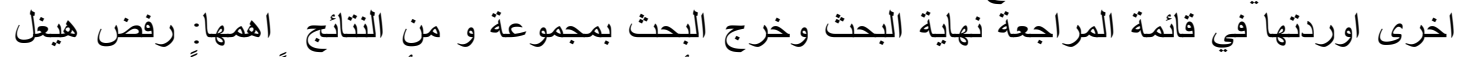

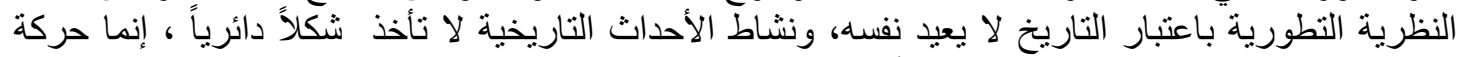

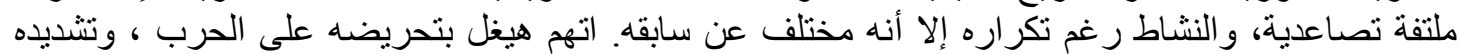

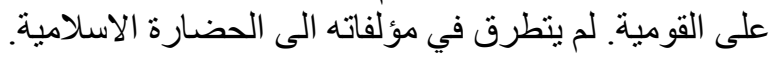

\section{المبحث الأول: حياة هيغل ومؤلفاته}

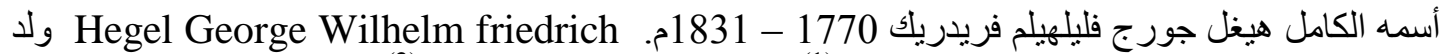

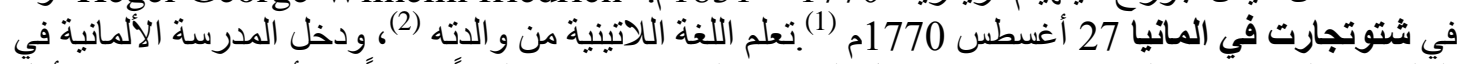

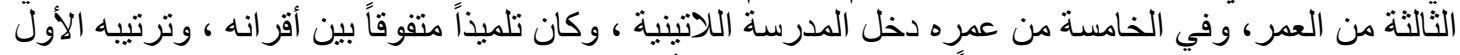

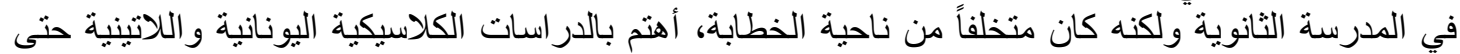

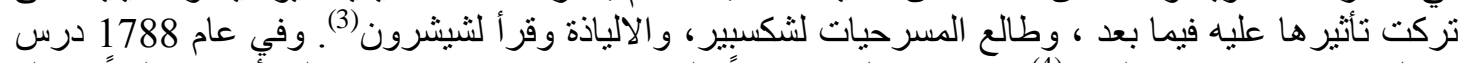

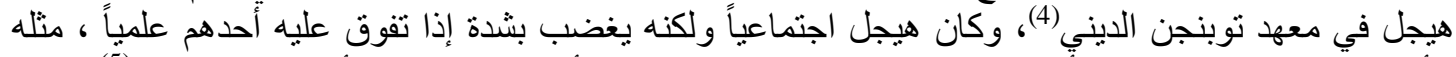

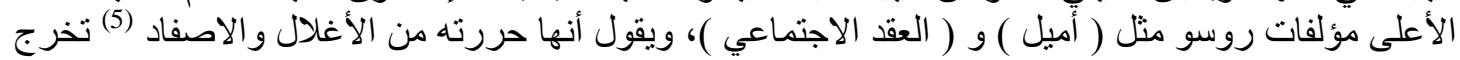

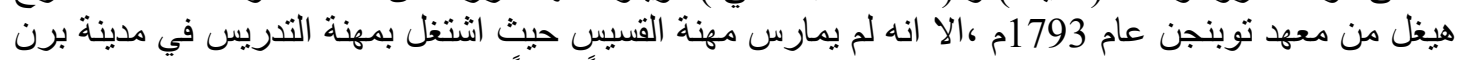

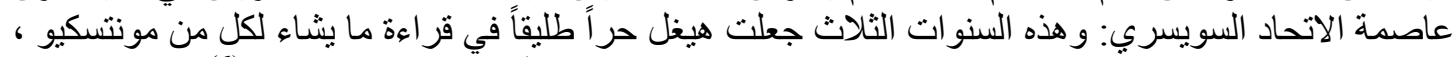

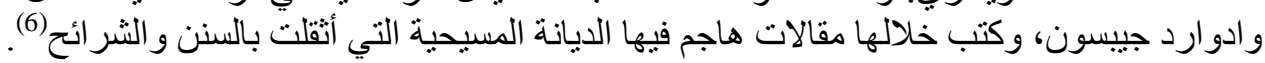

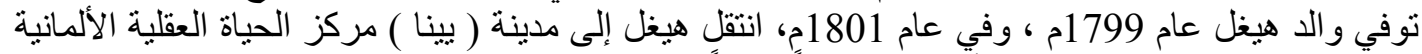

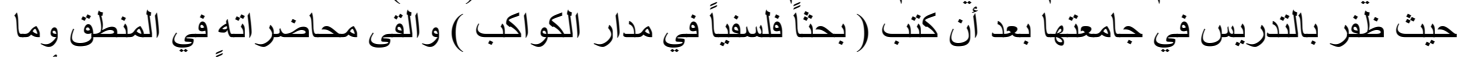

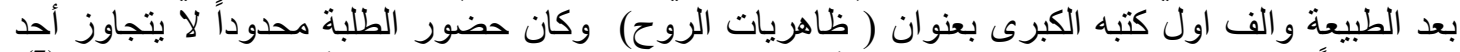

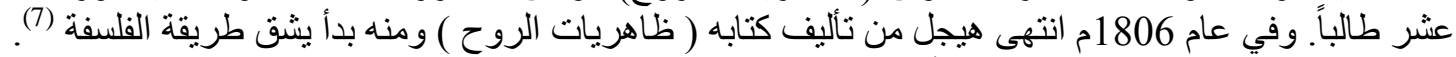

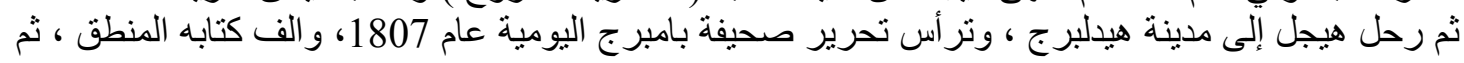

The new Encyclopacdia Britannica, vol 20,p.551 Ibid,vol 20 , p551

(3 ) إمام عبد الفتاح إمام ، المكتبة الهيجلية ( الدراسات ) ، الفلسفة السياسية عند هيجل، مكتبة مدبولي ، القاهرة ، 1996م

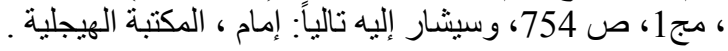

Ency, Brit, vol 20, p551

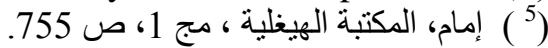

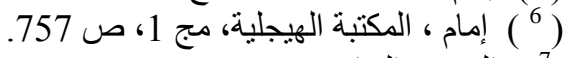

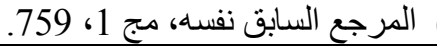




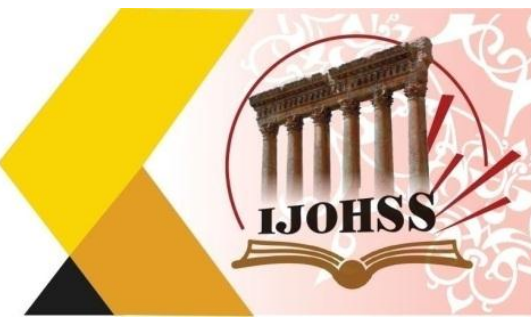

عمل مدير اً لمدرسة ثانوية في نورمبرج (1). مدة ثمان سنوات، درس فيها الفلسفة و الطبيعة و الرياضيات ، كما

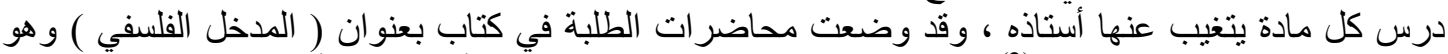

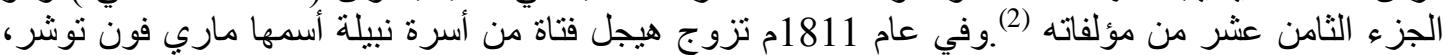

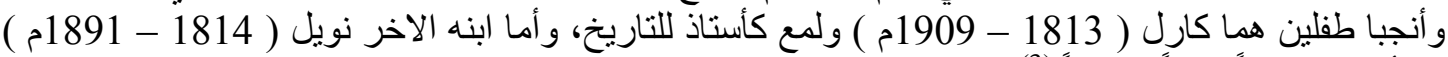

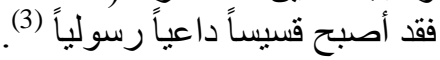
بعد وفاة الفيلسوف فشته فئهاً 1817م، خلا كرسي الفلسفة في جامعة هيدلبرغ في في برلين، فعين وزير التعليم هيجل

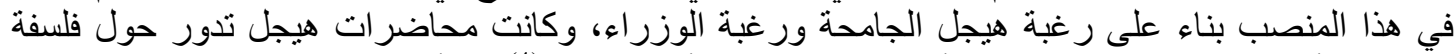

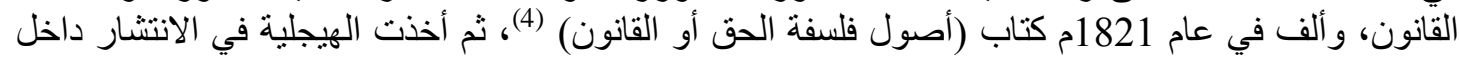

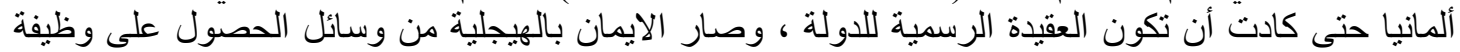

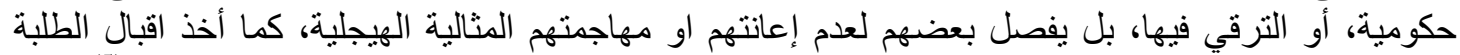

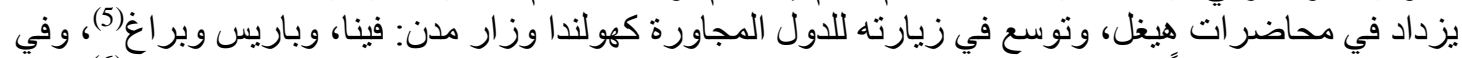

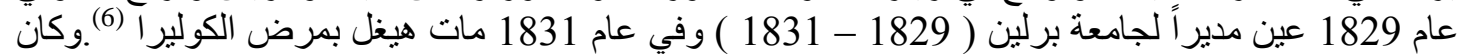

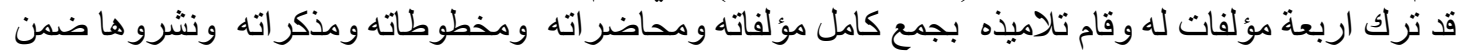

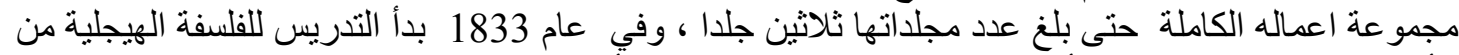

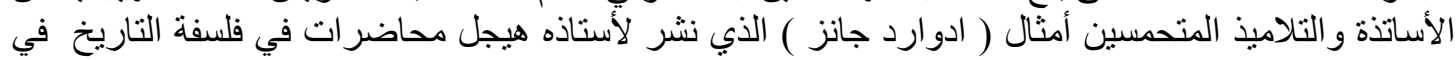

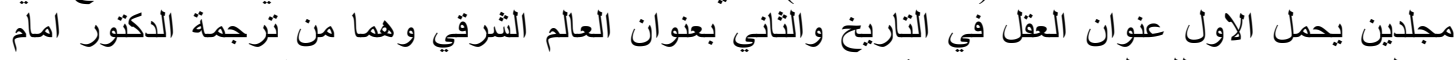

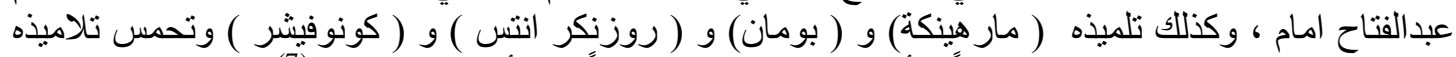

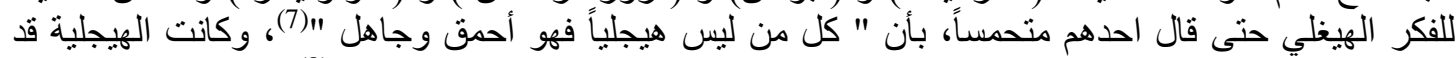

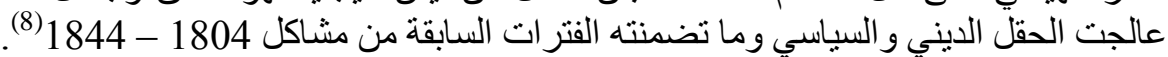

مؤلفات هيغل القلسفية (9)

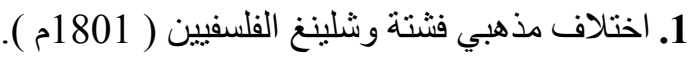

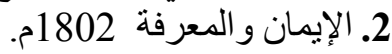
3. فينومينولوجيا العقل 1806م، 1802م و عرض الكين فيه لتطوير نمو العقل. 4. المنطق الكبير 1812 - 1816م. وبنيا 1816 وعنين فيه أن المطلق هو الفاعل الحقيقي لكل ناريخ، وهو أكثر الكتب أهمية. 5. 5وسو عة العلوم الفلسفية ( 1817م 1817م). 6. فلسفة الحق 1821م أو القانون، وفيه يبين أن التاريخ وجود و اقعي هو تاريخ عقل يتجاوز الفردية ويتجسد في

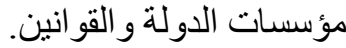
7. مبادئ فلسفة الحق، ودرس هيغل الحق ضمن إطار فلسفة التاريخ الذي هو تحقيق جدلي للحرية في الحق

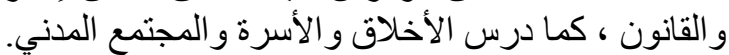
8. 8حاضر ات هيغل في تاريخ الفلسفة.

( ) ترأس تحرير مجلة غازيت دي بامبرنج ، أنظر رولي إيلي ألفا ، موسو عة أعلام الفلسفة، العرب و الأجانب ، قدم لله

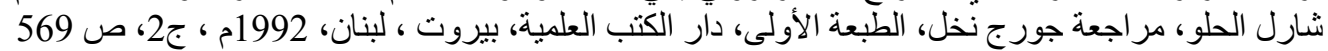

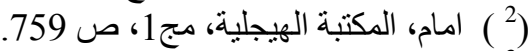
(Ency, Britan, Hegel and Hegelianism, vol 20,p 553 ( ${ }^{3}$ ) Ibid, vol , p553 $\left({ }^{4}\right)$

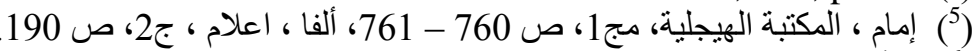

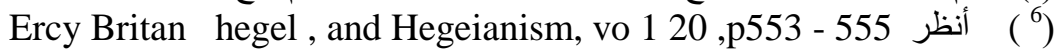

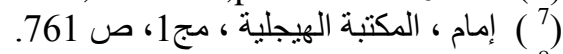

Ercy, Britan,Hegelianism, vo 20 p $555-558 . \quad\left({ }^{8}\right)$

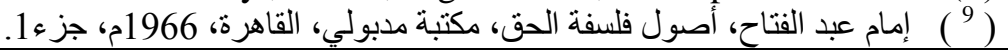




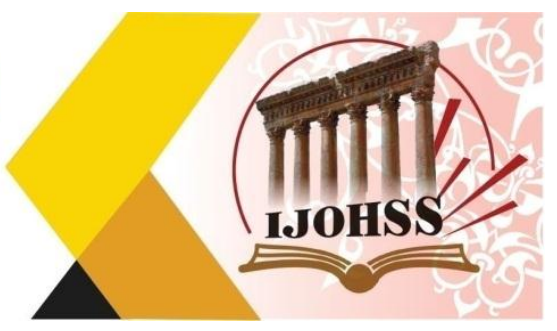

ولم تقتصر مؤلفاته على الفلسفة، بل شملت فروع معرفية أخرى كالتاريخ والفن والجمال و السياسة و الدين

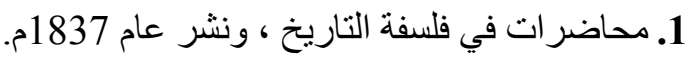
2. 2. محاضر ات في فلسفة الدين.

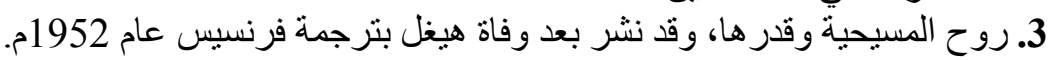

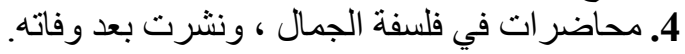
5. حياة يسوع 1795م، ونشر إنسر بعد وفاته.

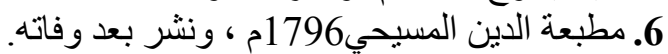
7. روح المسيحية ومصير هالئ 1799م.

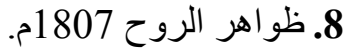

\section{المبحث الثاني: مصادر فلسفة هيجل}

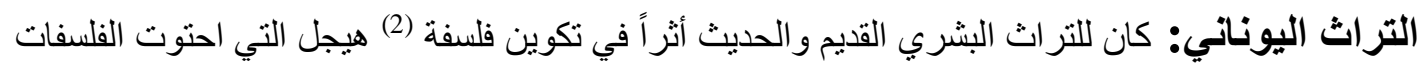

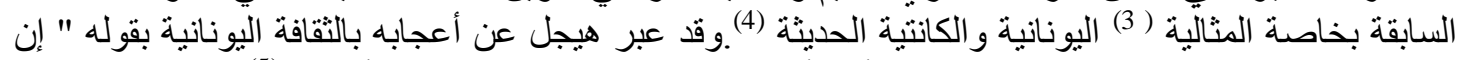

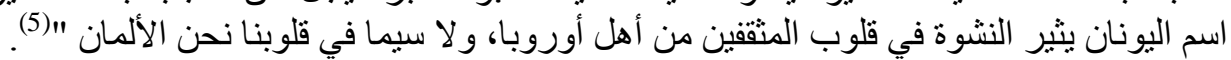

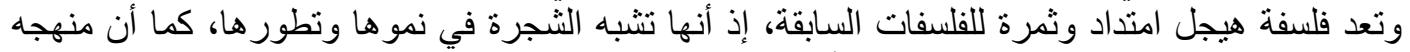

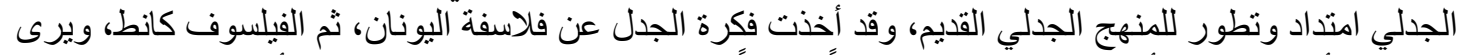

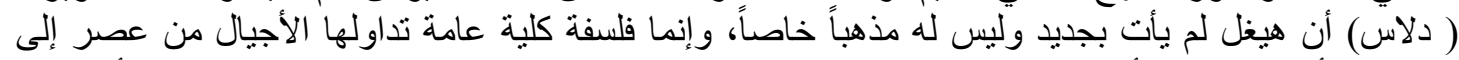

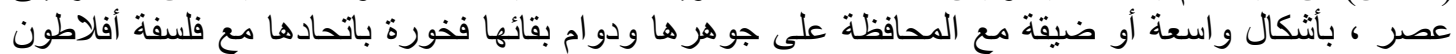

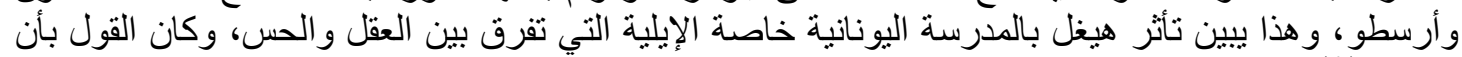

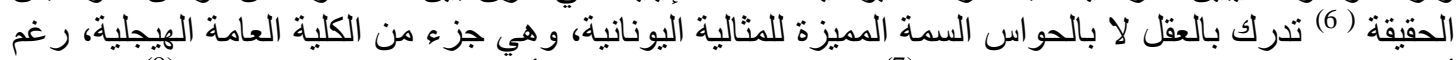

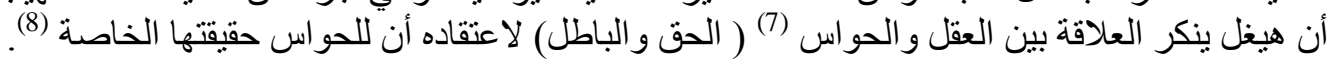

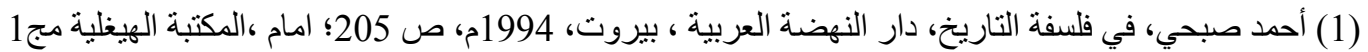

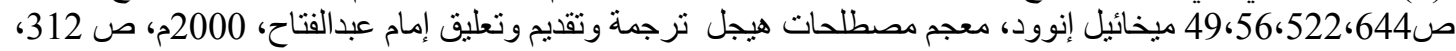

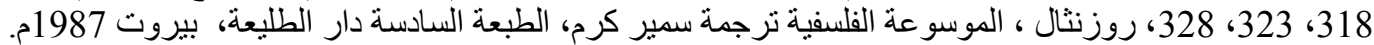

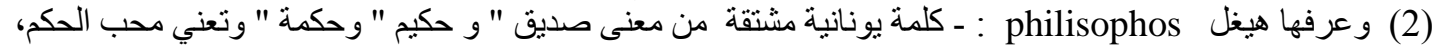

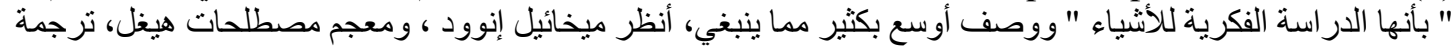

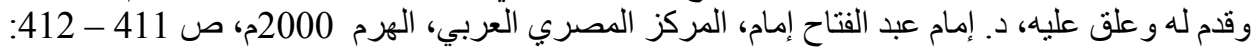

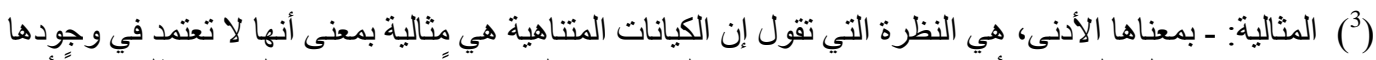

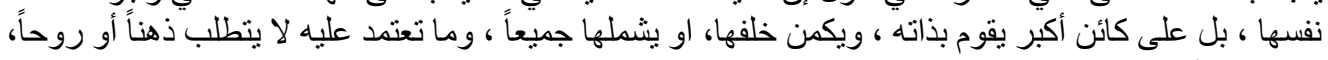

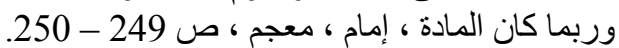

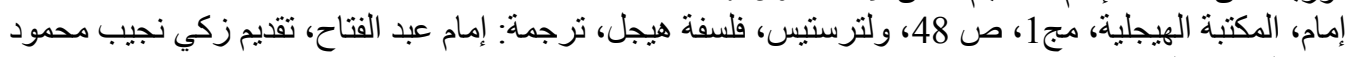

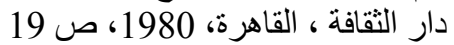

(5) إمام، المنهج الجدلي عند هيجل" در اسة لمنطق هيجل" الطبعة الثالثة، بيروت ـ لبنان، 1986، ص 42،

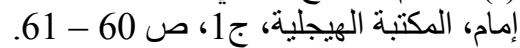

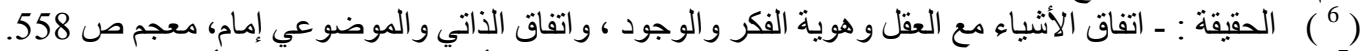

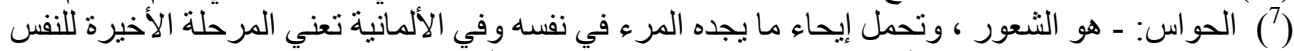

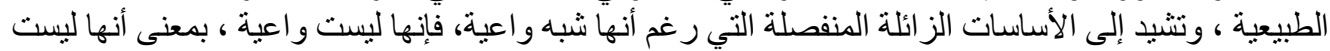

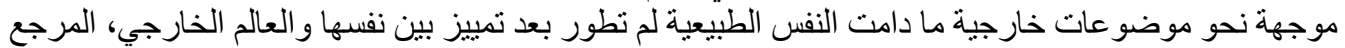

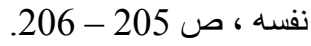
ستيس، فلسفة هيجل، ص 19 - 205. 


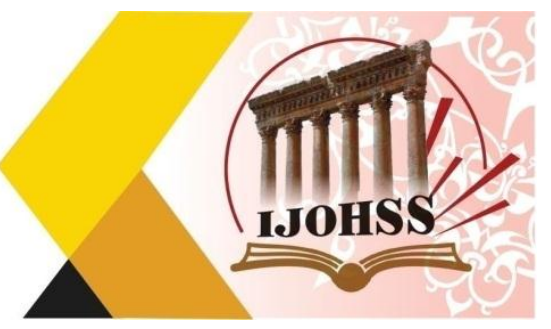

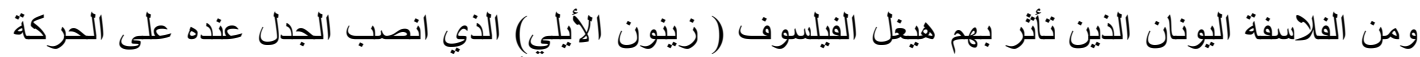

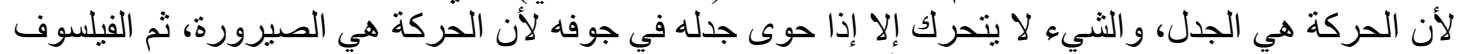

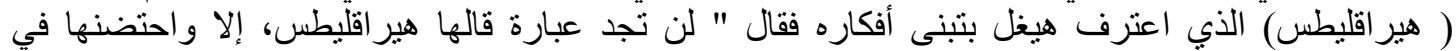

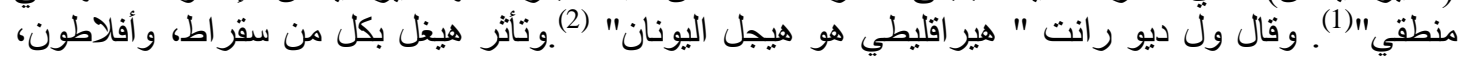

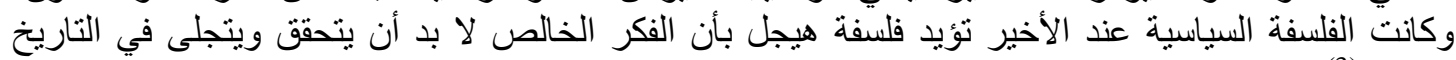
البشري(3).

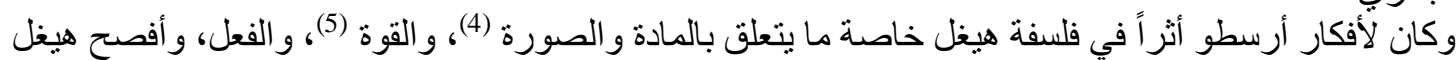

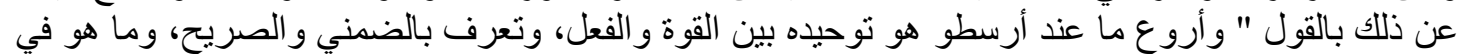

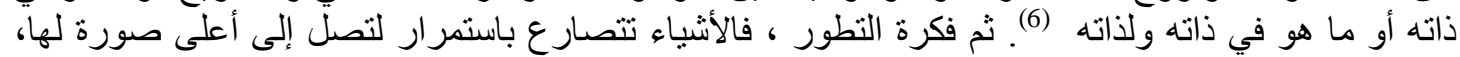

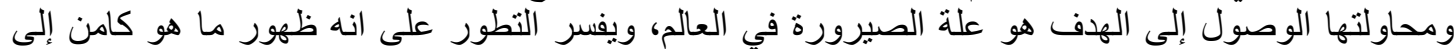

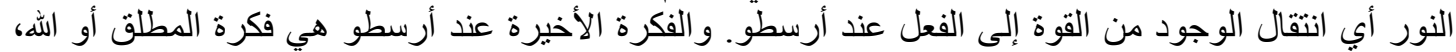

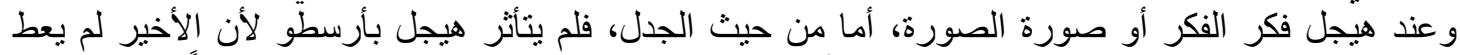

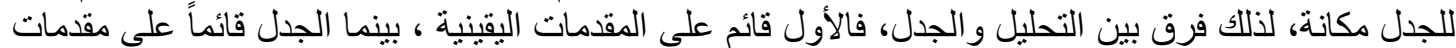

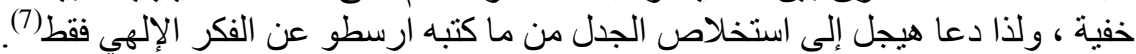

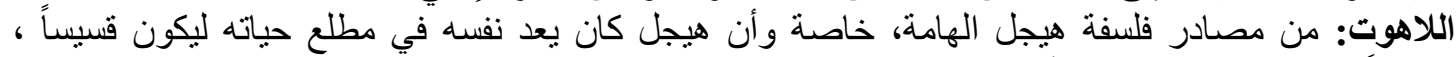

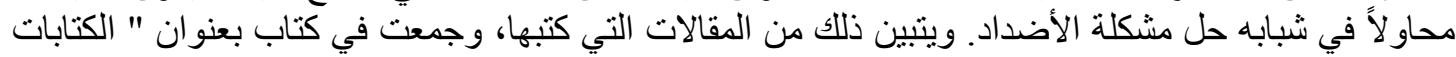

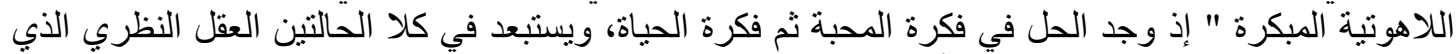

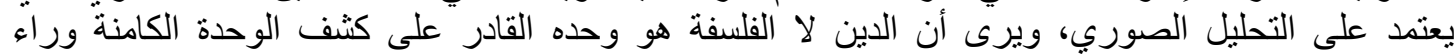

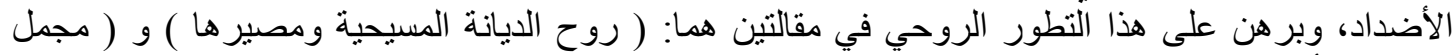

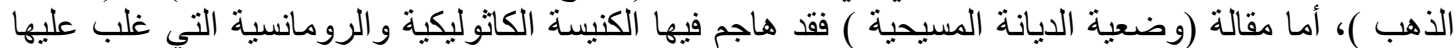

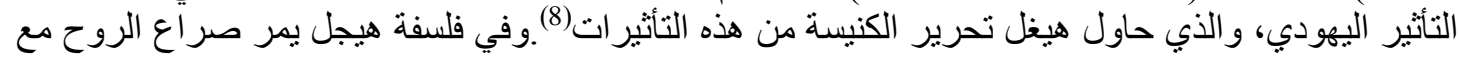

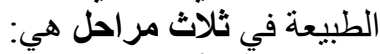

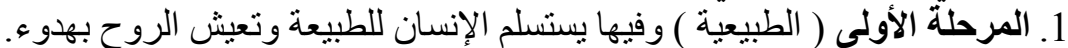

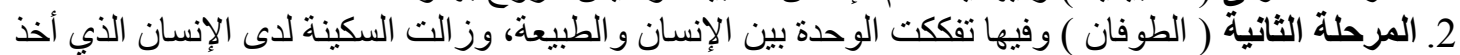

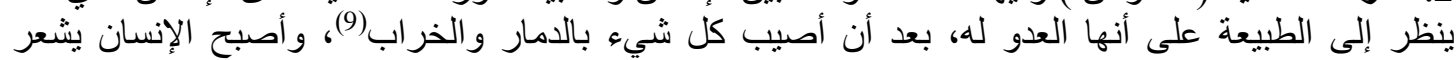

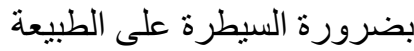
3. المرحلة الثالثة ( إعادة الوحدة بالفكر ) أو انتصار الروح على الثلى الطبيعة، يمثل الصر اع بين الخير و الثر (10).

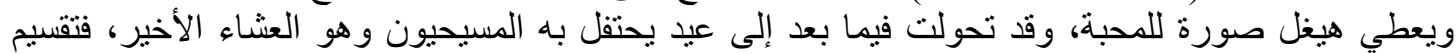
الخبز وشرب الخمر لديهم لا يعني الطعام والثراب ، لكن لله مضمون آخر هو أنهم أنخاص متعددون ، ولكن الثن

$$
\text { إمام ، المكتبة الهيجلية ص } 68 \text { (إمبام }
$$

Hegal , The history of philosophy , vo1, p.278

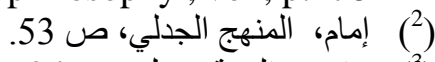

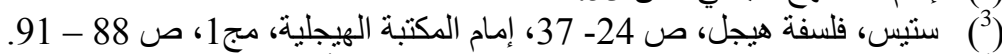

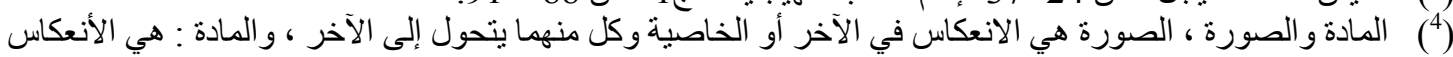

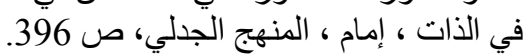

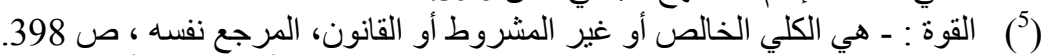

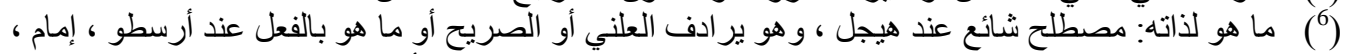

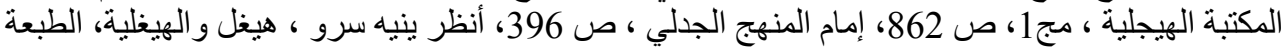

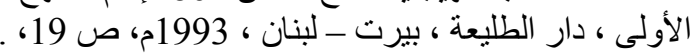

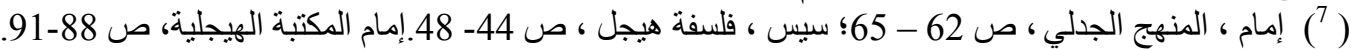

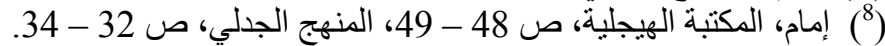

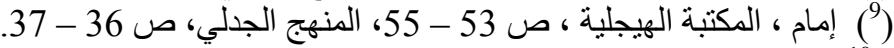

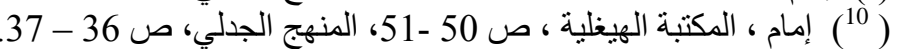


International Journal on Humanities and Social Sciences

website:www.ijohss.com

Email:editor@ijohss.com

العدد (29) ل يناير 2022

ISSN: $2415-4822$

Volume (29) January 2022

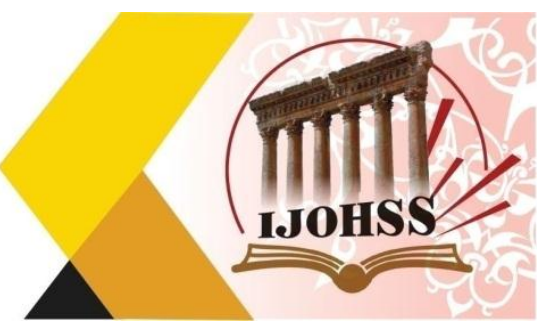

بالمحبة يصبحون شيئًاً واحداً هو الروح، إذ تتلاشى الاختلافات، فالمحبة تعيد الإنسان إلى وحدة الإنسان

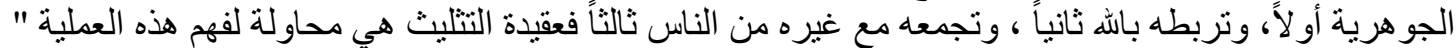

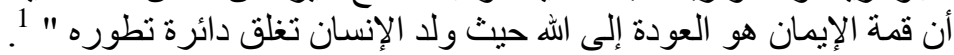

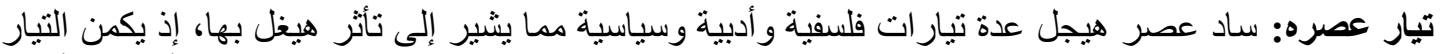

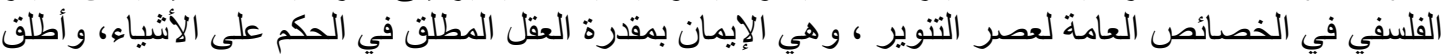

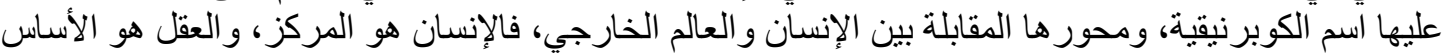

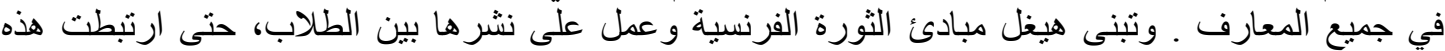

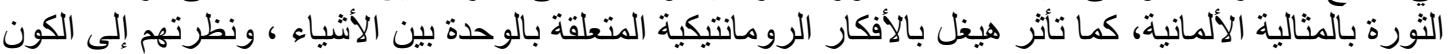

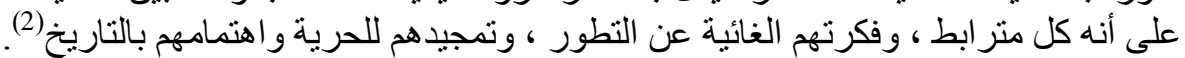

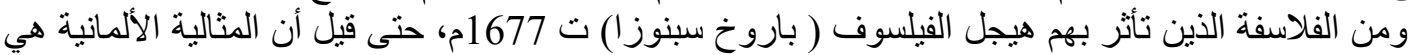

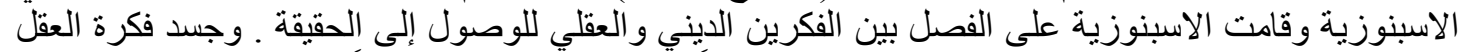

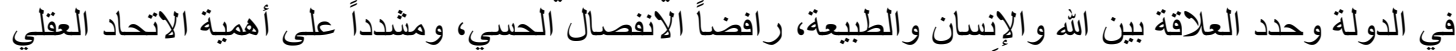

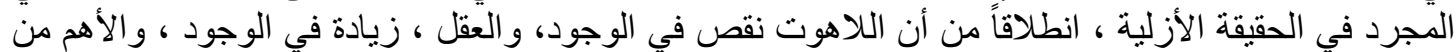

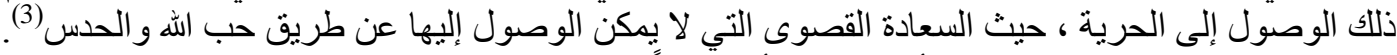

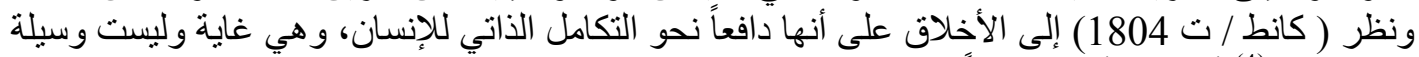

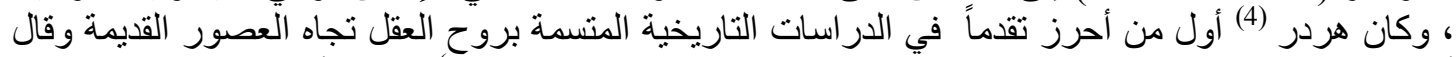

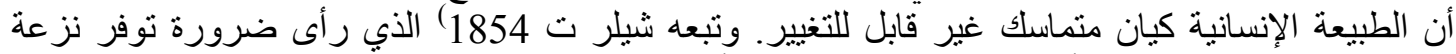

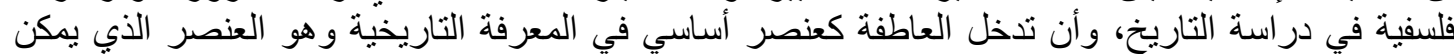

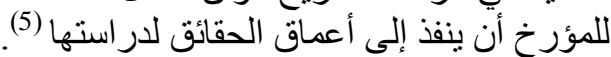

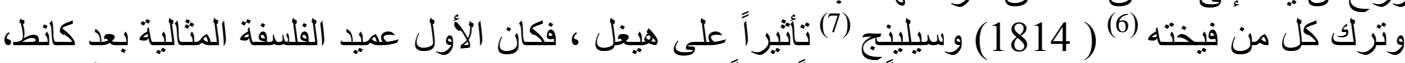

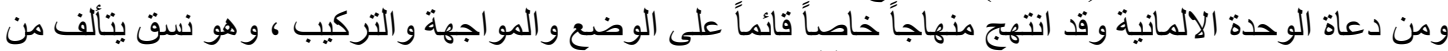

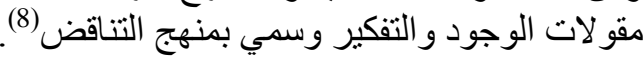

$$
\begin{aligned}
& \text { (1) إمام الجدل العيغلي، ص } 76 \text { - } 77 \text { - } 77 . \\
& \text { (2) المصدر السابق نفسه ، ص صل } 78 \text { - } 79 .
\end{aligned}
$$

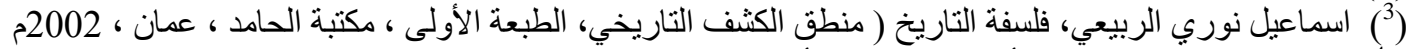

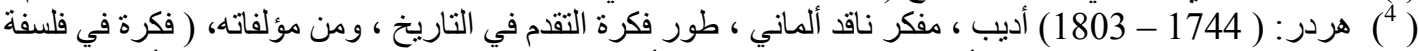

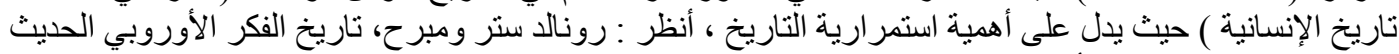

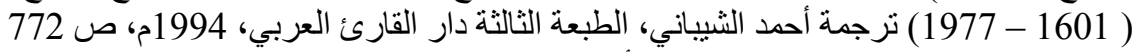

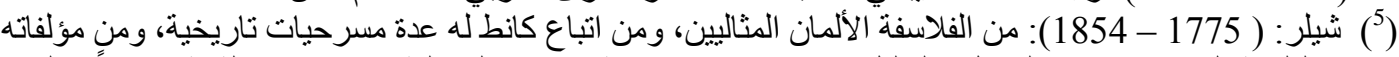

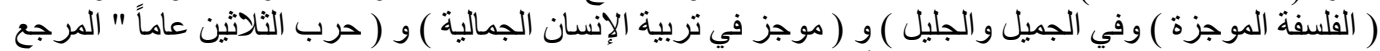

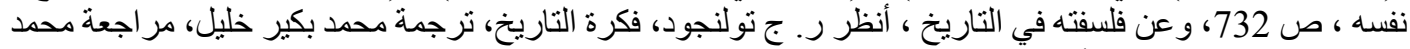

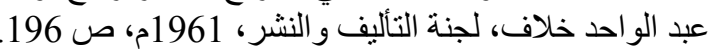

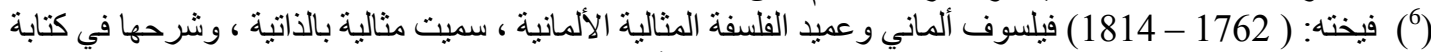

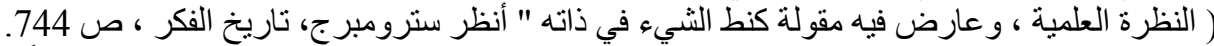

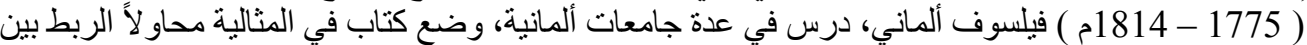

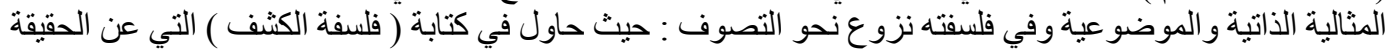

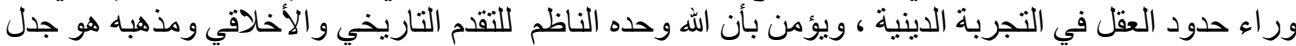

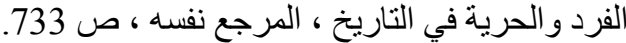

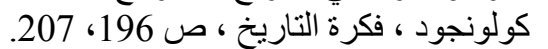




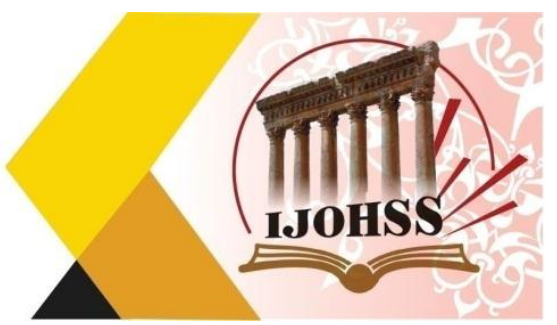

المبحث الثاني: المنهج الجدلي اللهيغلي

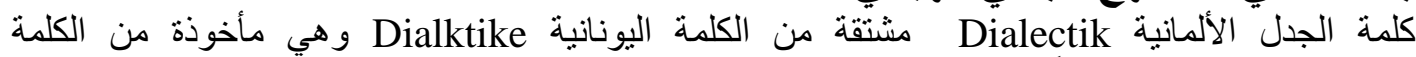

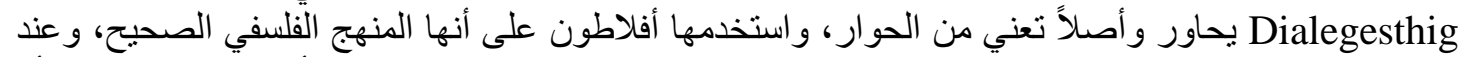

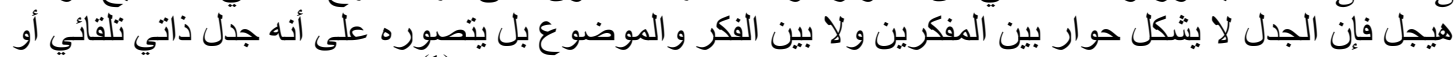

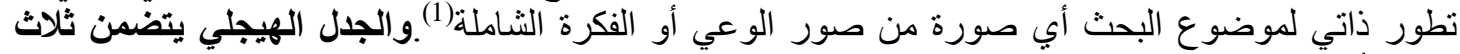

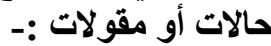

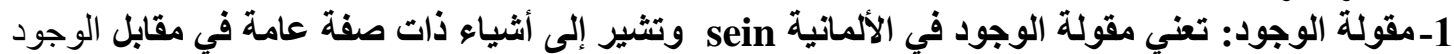

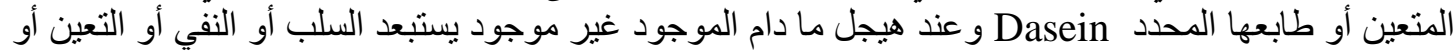

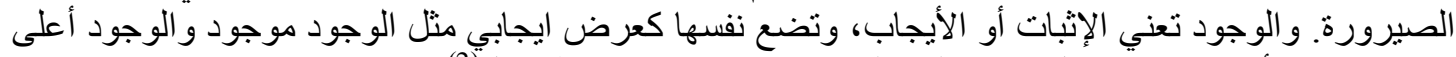

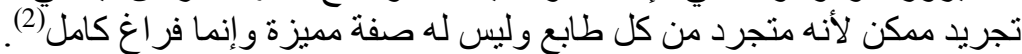

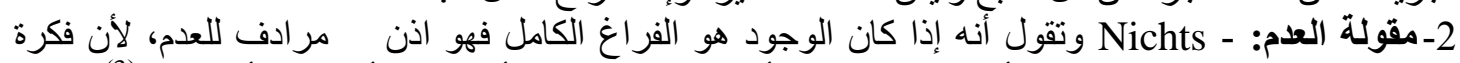

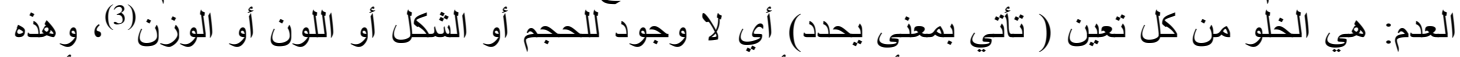

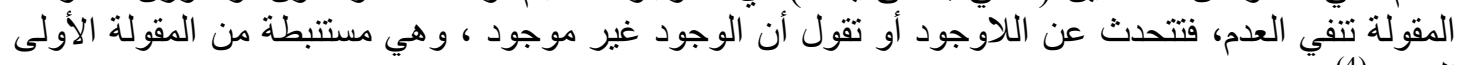
الوجود (4) - (4).

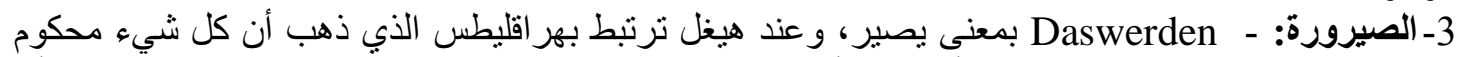

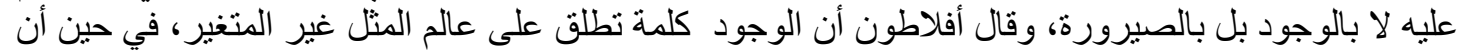

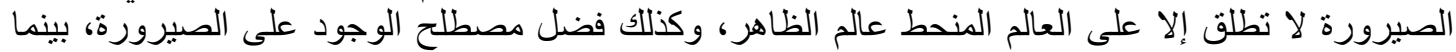

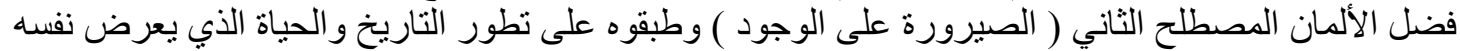

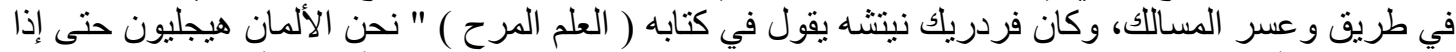

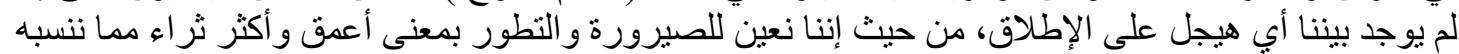

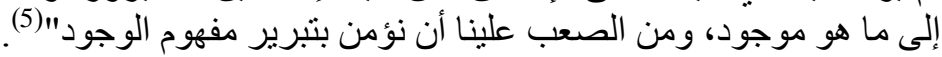

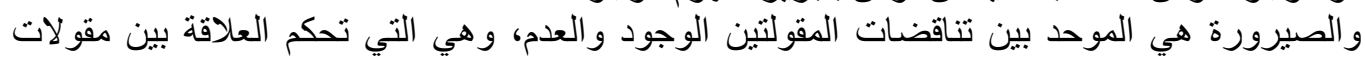

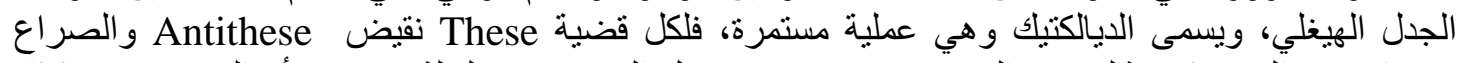

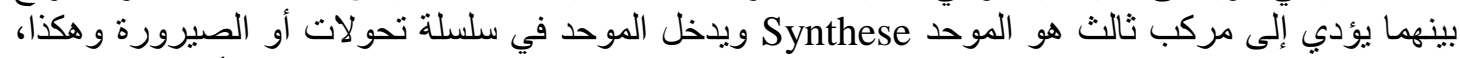

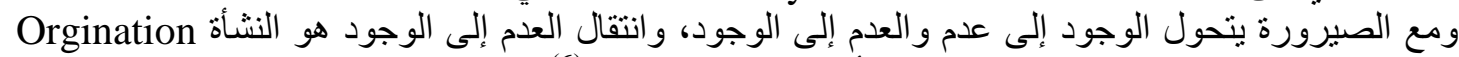

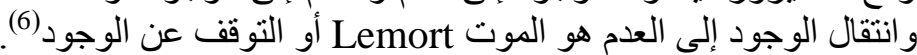

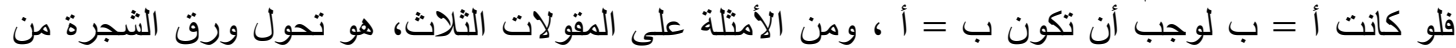

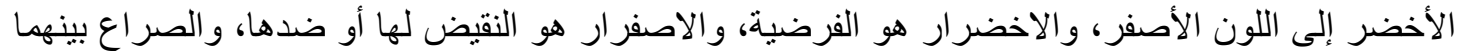

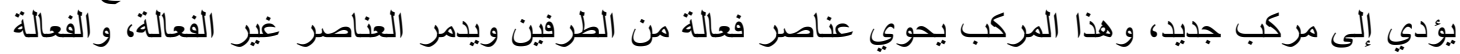

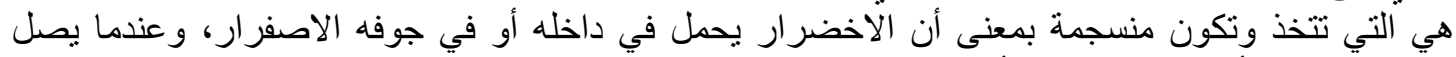

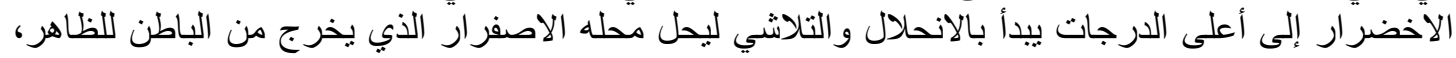

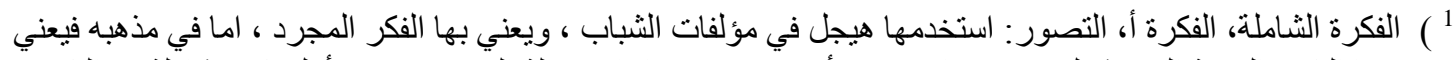

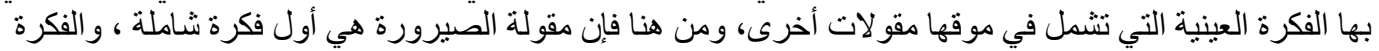

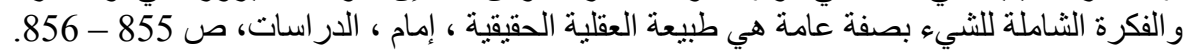

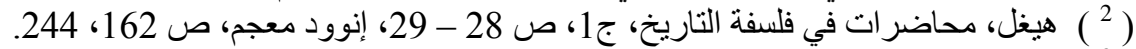

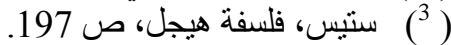
(5) محمد مر اد ، المدارس التاريخية ، الطبعة الأولى ، بيروت ـ لبنان، 1996م، ص 188 18 ، المدارس هيغل، محاضرات

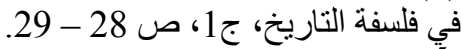
( )

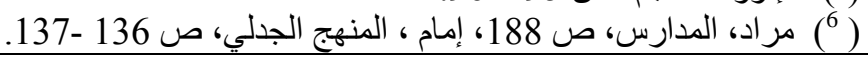


International Journal on Humanities and Social Sciences

website:www.ijohss.com

Email:editor@ijohss.com

العدد (29) يناير 2022

ISSN: $2415-4822$

Volume (29) January 2022

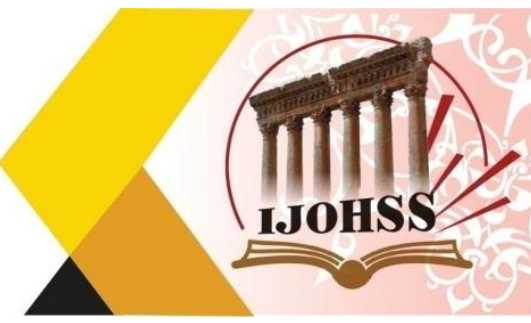

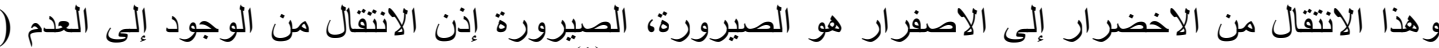

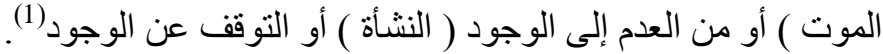

المبحث الثالث: فلسفة التاريخ الهيظلية

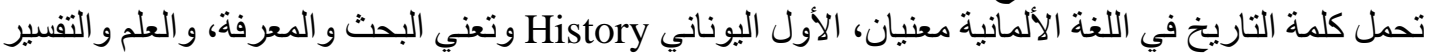

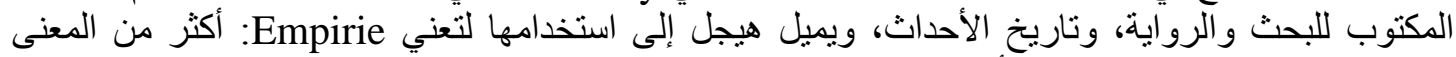
التخصيص ( التجربة التاريخية والأحداث)

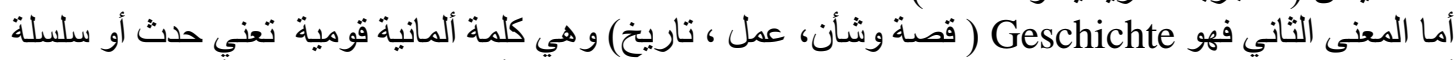

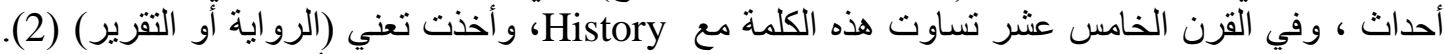

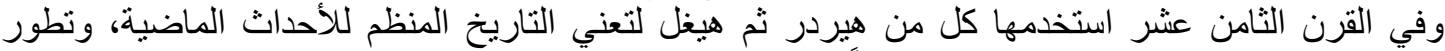

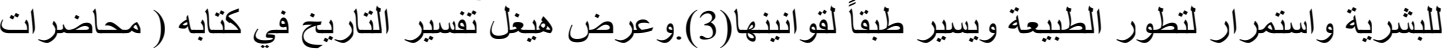

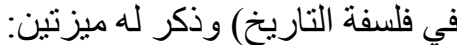

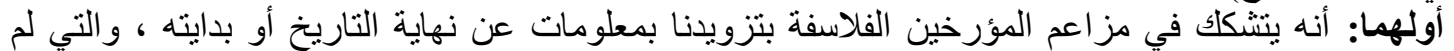

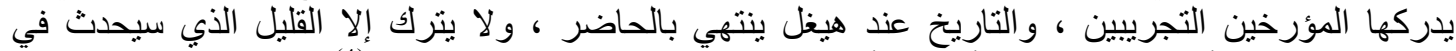

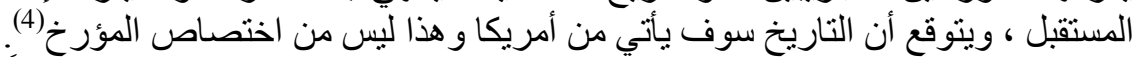

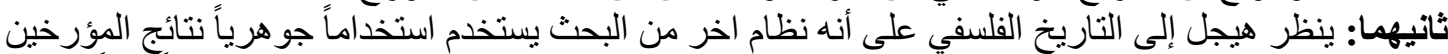

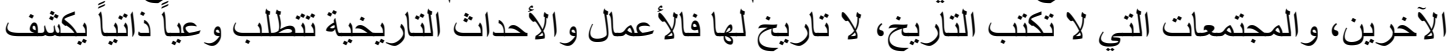

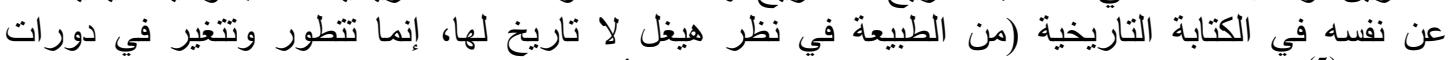

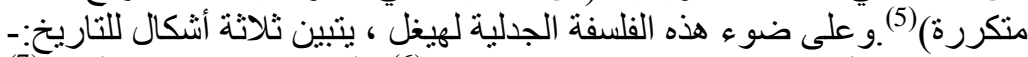

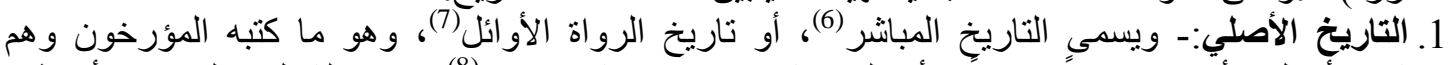

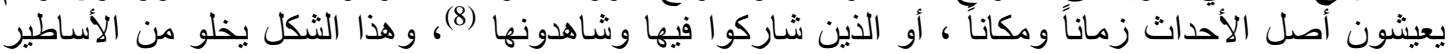

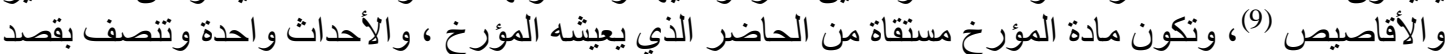

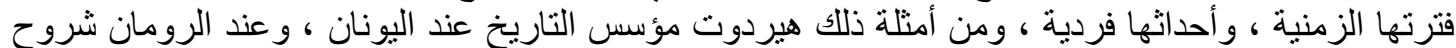

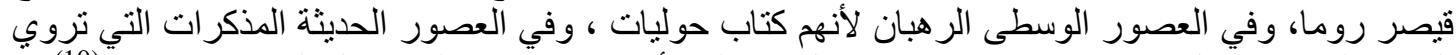

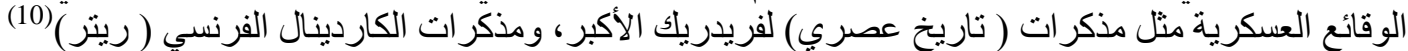

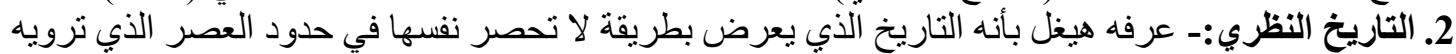

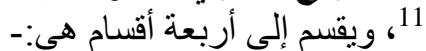

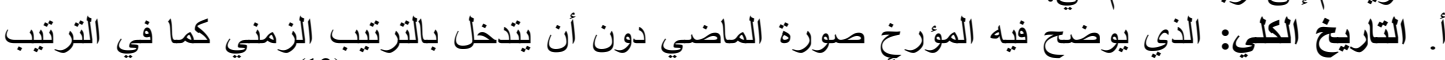

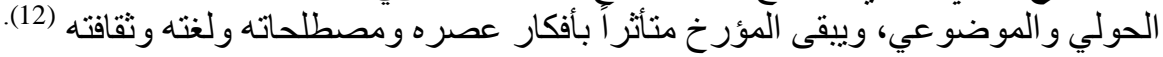

$$
\text { (إ) (اد مر اد، ، المدارس، ص صن 190، ستيس ، فلسفة هيجل، ص } 198 \text { - } 199 .
$$

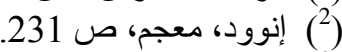

(3) ب. ت غريفوريان، الفلسفة وفلسفة التاريخ، ترجمة هيثم طه ، مر اجعة رضو ان القضماني، دار الفار ابي، بيروت لـبنان

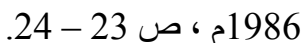

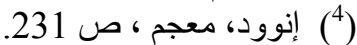

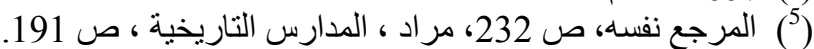

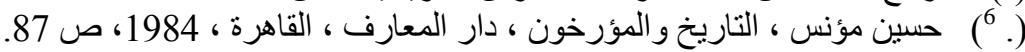

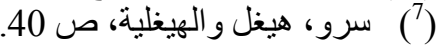

(8) (8) صبحي، في فلسفة التاريخ.

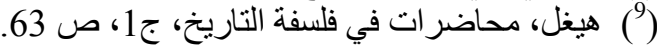

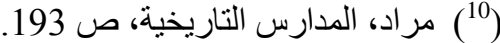

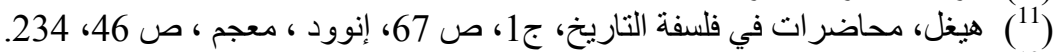

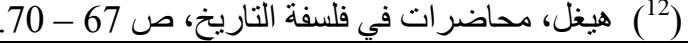


International Journal on Humanities and Social Sciences

website:www.ijohss.com

Email:editor@ijohss.com

ISSN: $2415-4822$

العدد (29) يناير 2022

Volume (29) January 2022

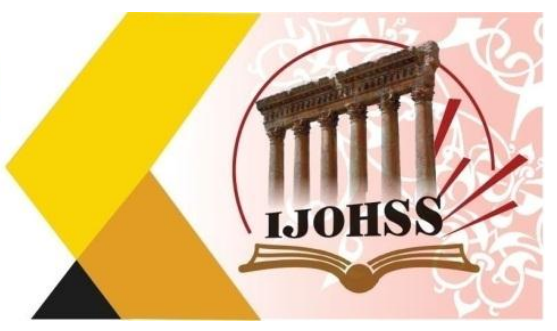

ب. التاريخ البرجماتي ( العملي): وهو التاريخ الذي يستخلص منه المؤرخ العبر والحكم ، وينفي هيغل أي

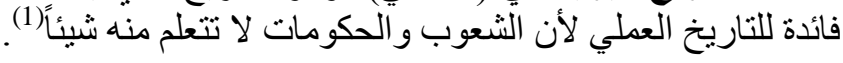

3. التاريخ النقاي: و هو نقد الروايات التناريخية الأخرى من حيث مصادر ها ومعقوليتها في ناريخ التاريخ(2).

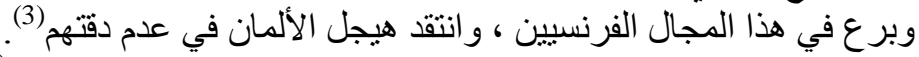

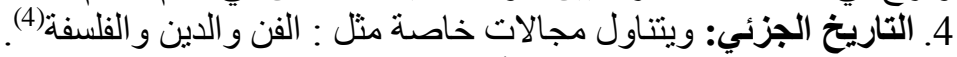

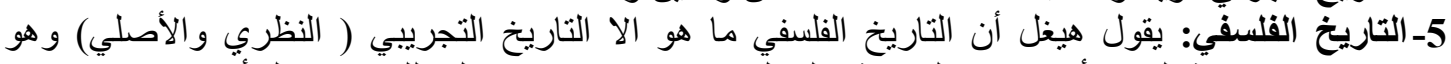

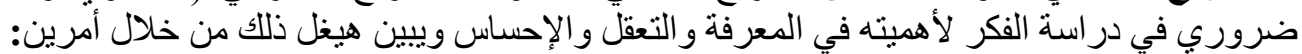

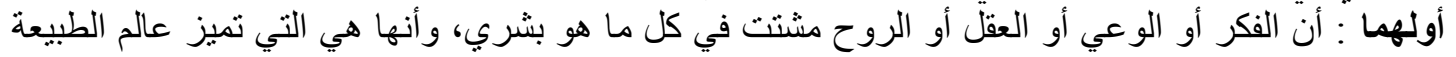

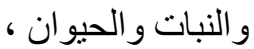
ثانيهما : ارتباط التاريخ بالوعي الإنساني، إذ يقول هيجل إن النجان المتمعات البدائية الني عاثت الأساطير

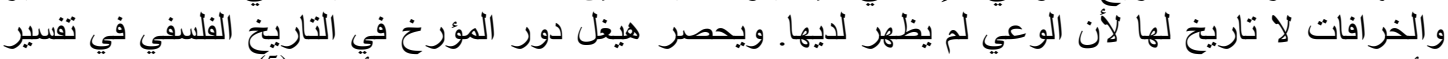

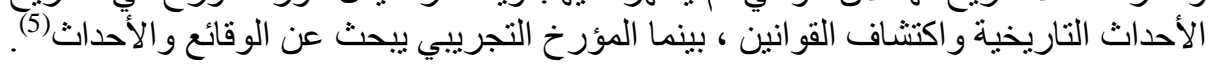

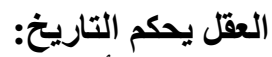

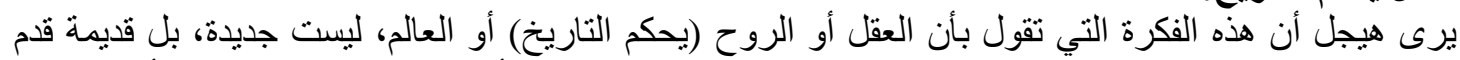

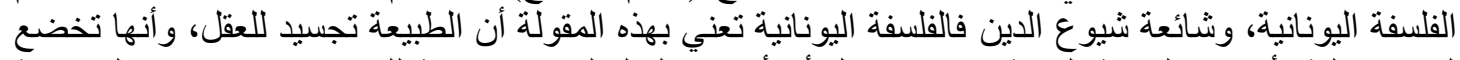

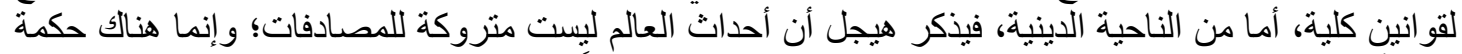

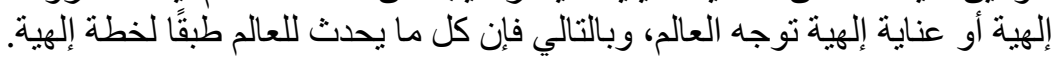

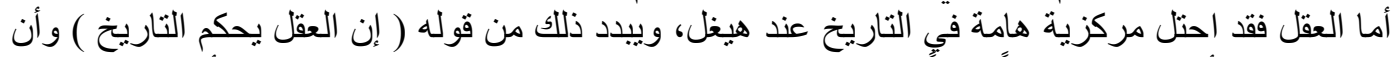

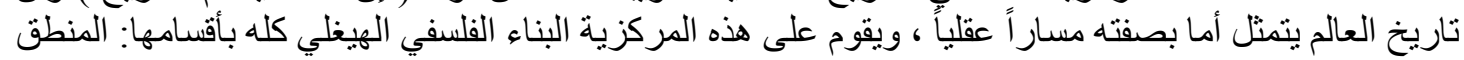

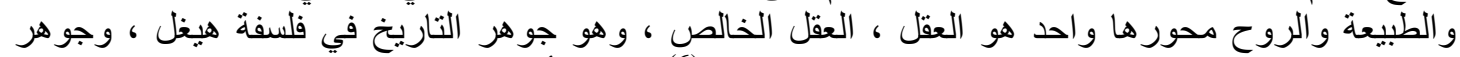

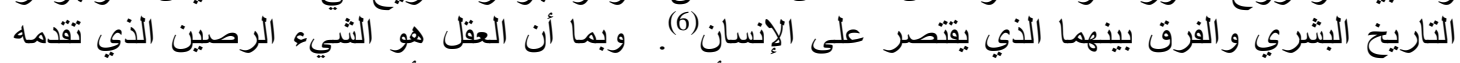

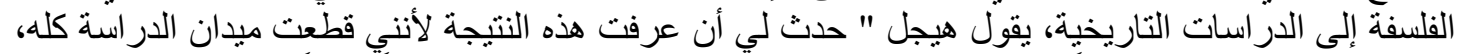

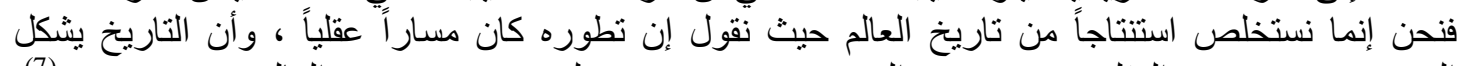

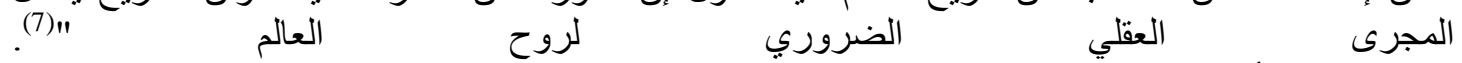
ويحاول هيجل أن يفسر ما يعنيه بقوله: "العقل يحكم التّاريخ"، من خلال ثُلاثة عناصر هي :

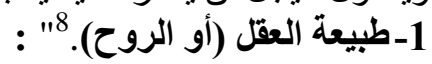

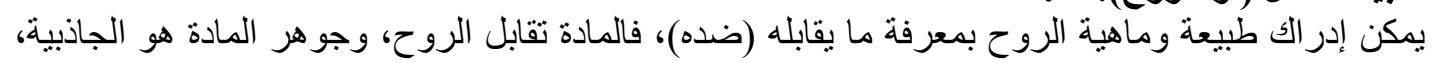

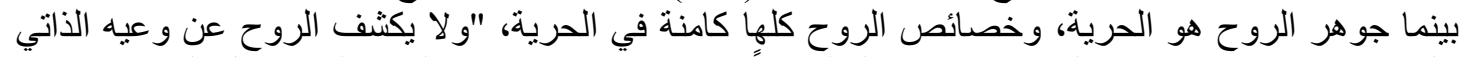

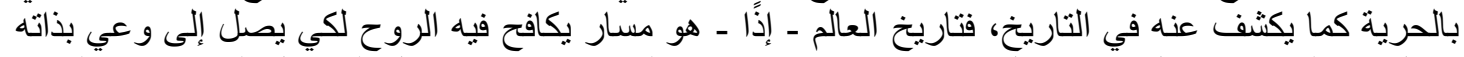

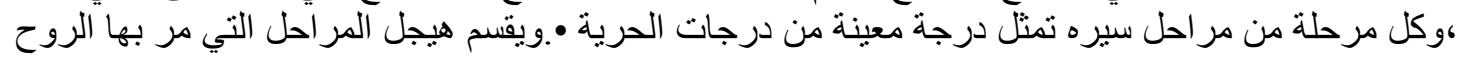
في سيره نحو الحرية إلى ثلاث مراحل:

\footnotetext{
(1) مؤنس ، التاريخ و المؤرخون، ص 87، مر اد ، الددارس التاريخية، ص 194، هيغل في فلسفة التاريخ، ج1، ص 70.

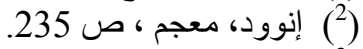
(3) مر اد، المدارس التاريخية ، ص ص 193، 193، مؤنس ، التاريخ و المؤرخون ، ص 92 - 93. هيغل ، محاضر ات في فلسفة

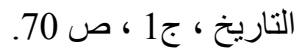

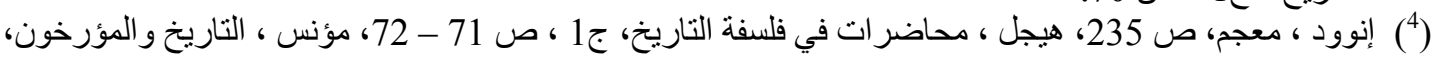

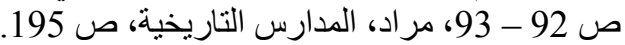

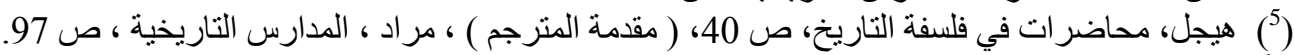

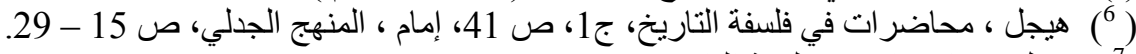

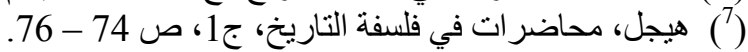

} 
International Journal on Humanities and Social Sciences

website:www.ijohss.com

Email:editor@ijohss.com

العدد (29) يناير 2022

ISSN: $2415-4822$

Volume (29) January 2022

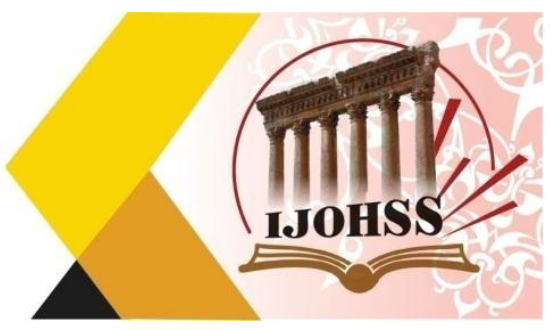

أ ـ المرحلة الاولى: تمثلها الحضار ات الثرقية القديمة؛ الصينية و الهندية و الفارسية و الفرعونية، وهذه المرحلة تتميز بأن المو اطنين جميعًا كانو ا عبيدًا للحاكم، وينفذون مشيئته، وهذا الحئنة الحاكم هو وحده الحر.

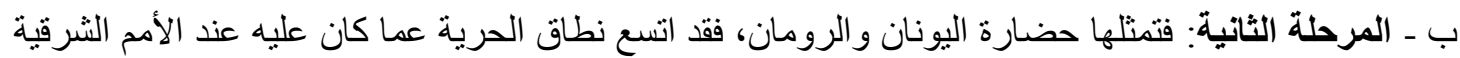

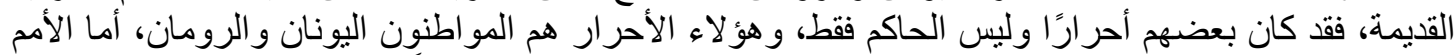

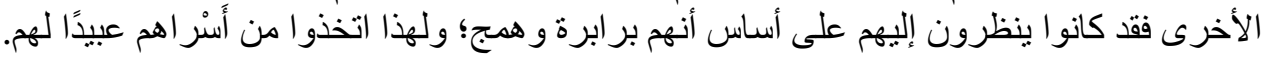

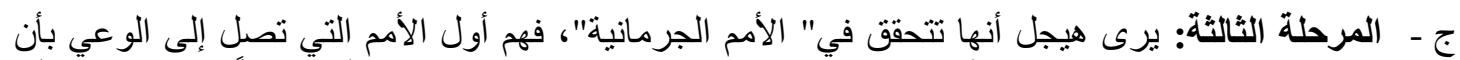

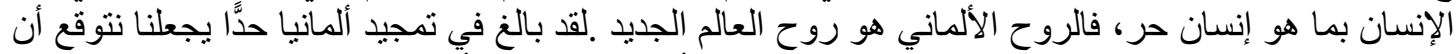

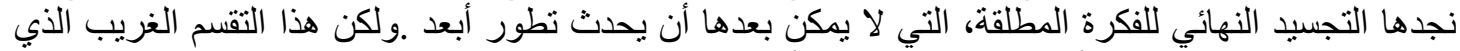

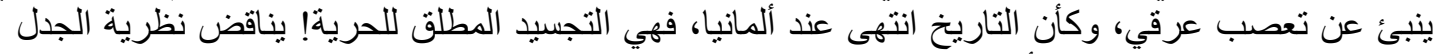

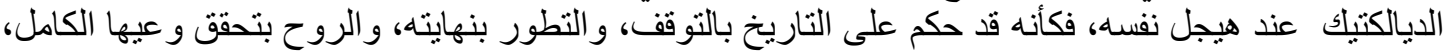

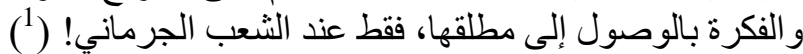

2-وسائل تحقق الروح في العالم: يرى هيجل أن "مشكلة الوسائل التي تطور بها الحرية نفسها في العالم، تقودنا

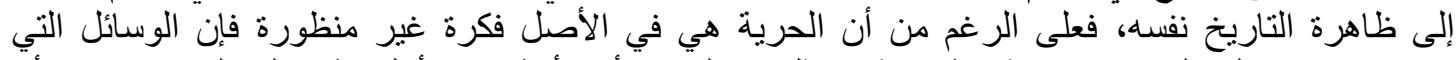

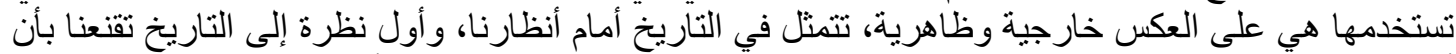

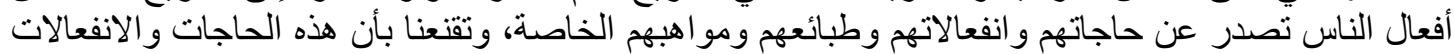

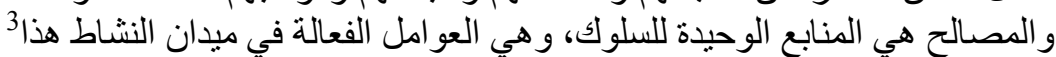

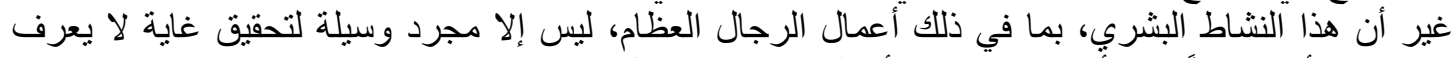

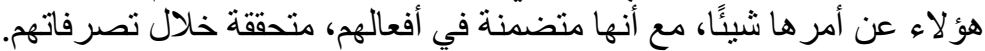

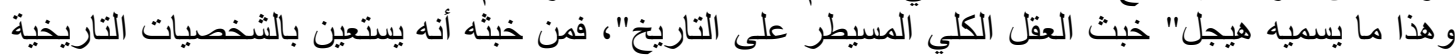

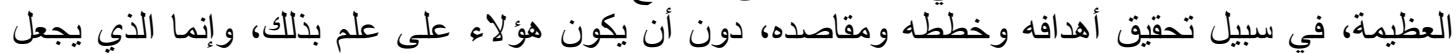

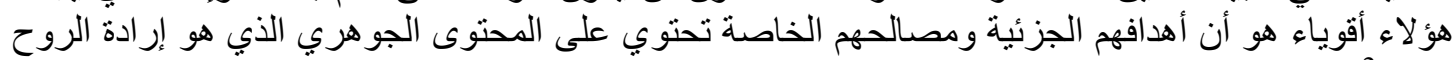
الكلية.

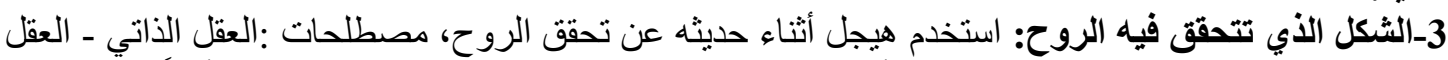

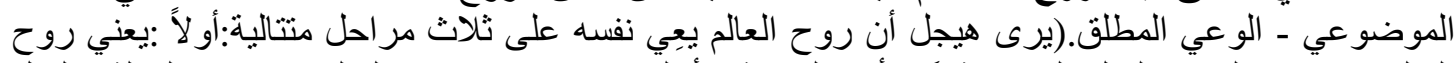

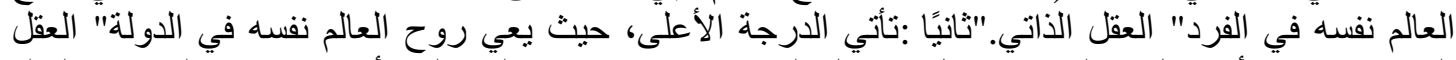

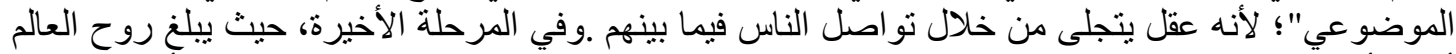

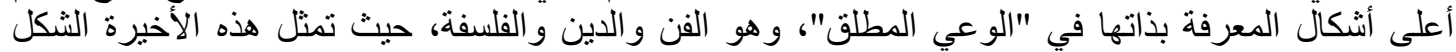

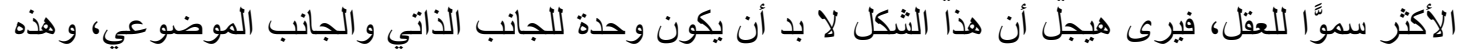

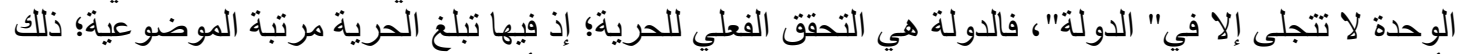

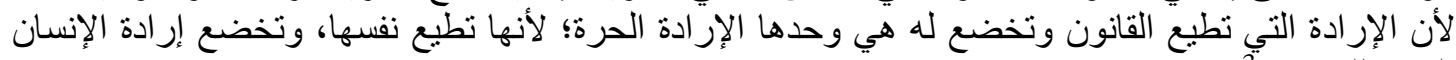

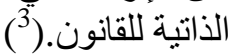

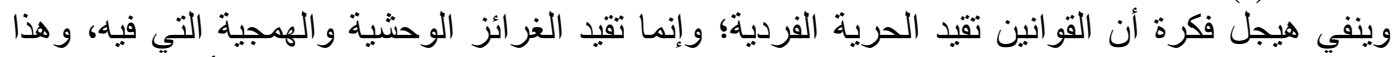

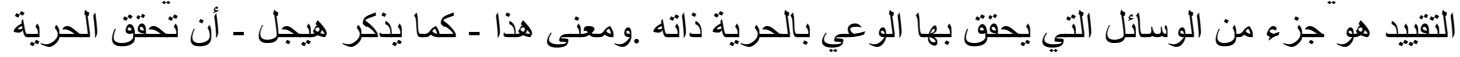

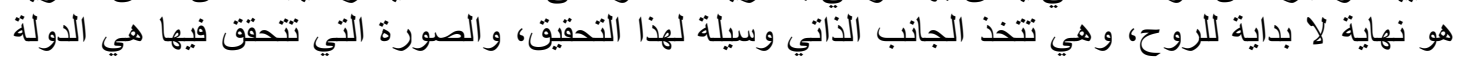

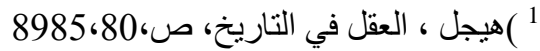
)بذوي، عبدارحمن ، موسو عة الفلسفة، المؤسسة العربية للاراسات والنشر ، الطبعة الاولى ، بيروت ، 1984 ج2

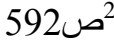
2) الثافعي سلمان ،فلسفة التاريخ عند الفيلسوف الألماني "هيجل 2014/12/25 رابط الموضوع: https://www.alukah.net/culture/0/80282/\#ixzz6iKSozDas" 


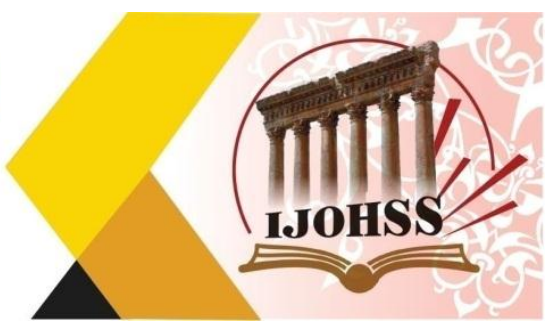

بوصفها الكلي الأخلافي، الذي يضم الجانبين الذاني و الموضوعي، ونشاط الروح كله ليس سوى هذه الغاية؛ أن

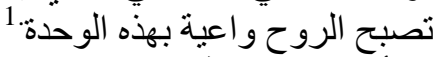

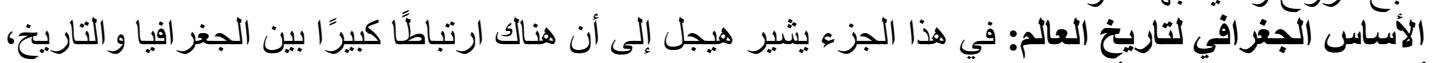

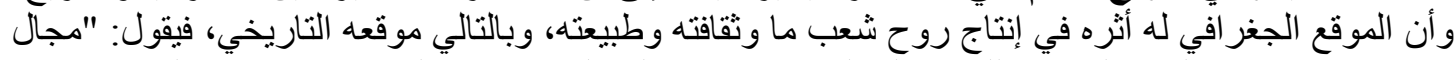

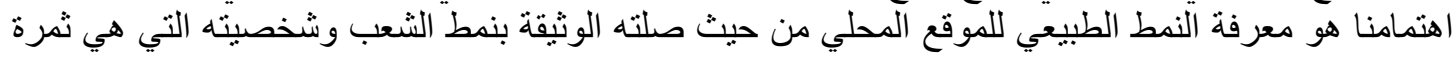

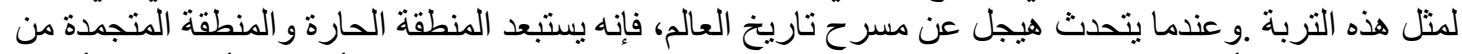

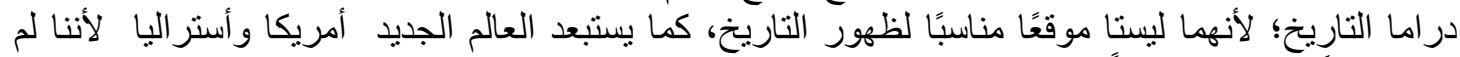

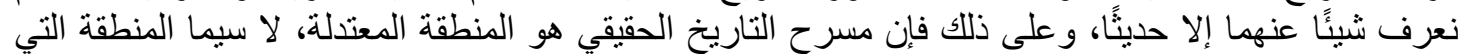

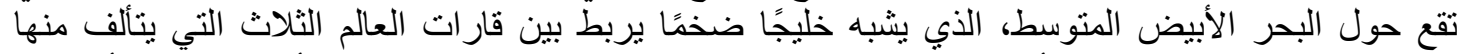

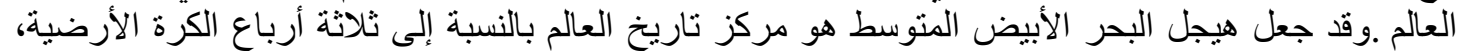

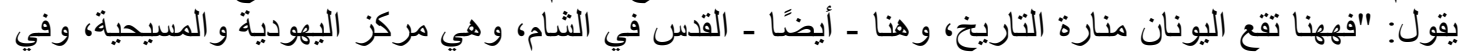

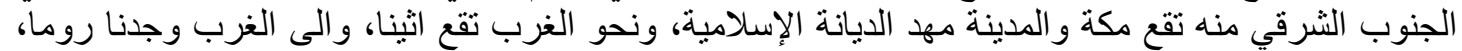

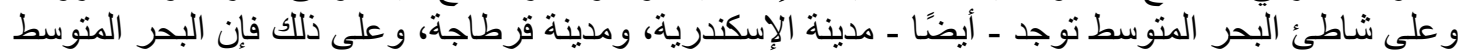

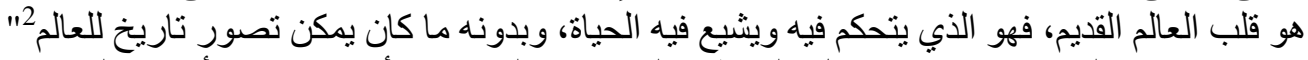

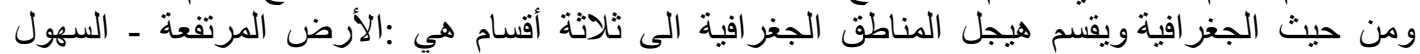

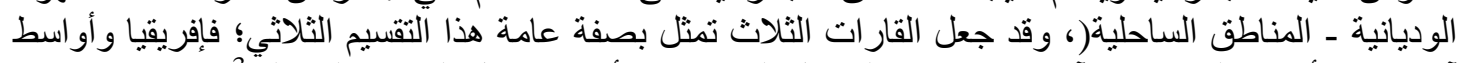

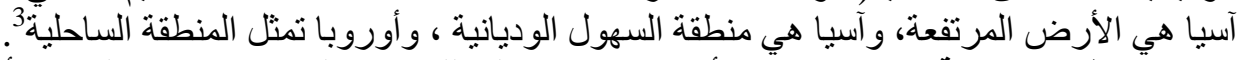

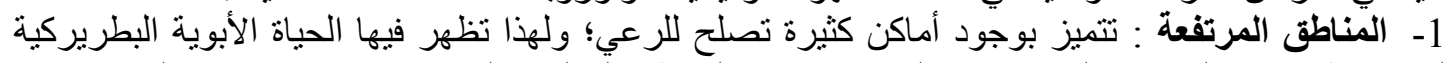

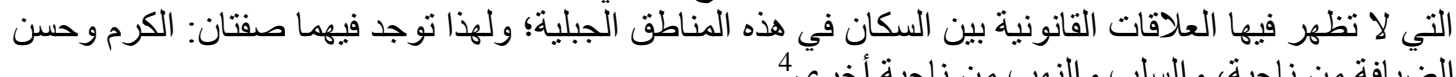

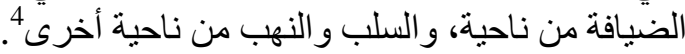

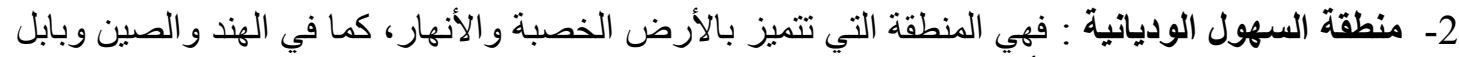

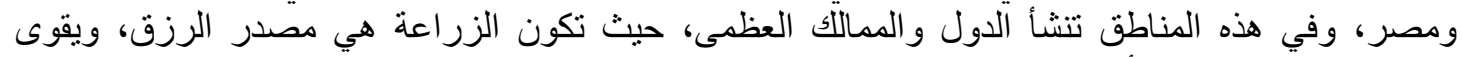

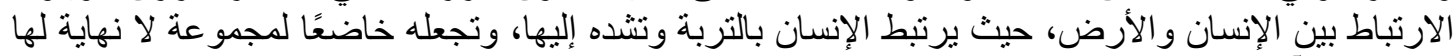

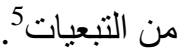

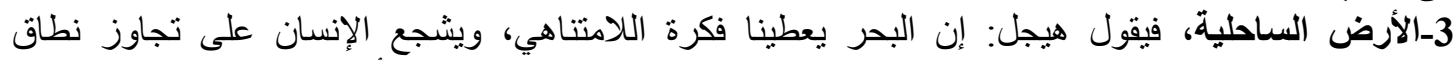

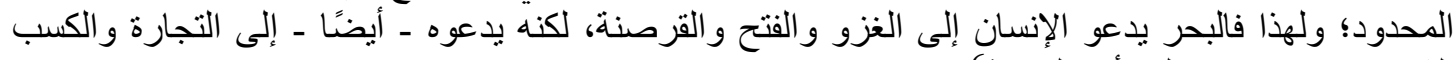

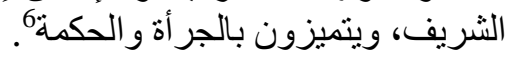

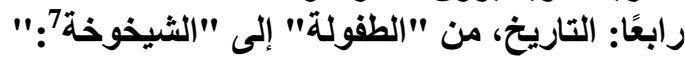

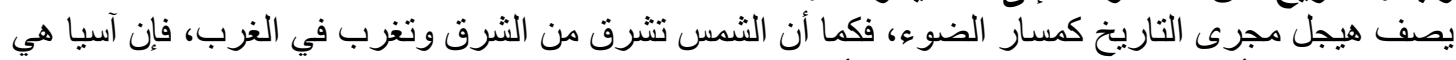

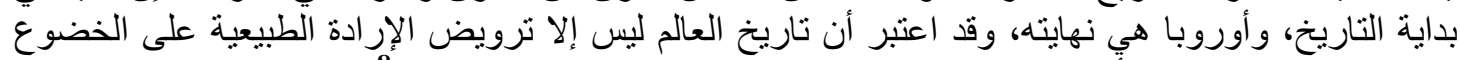

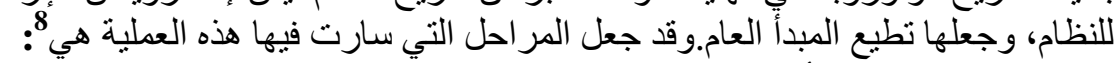

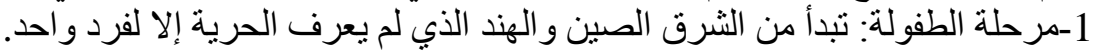
2- مرحلة الصبا: وتمنلها بلاد فارس ومصن الثرى

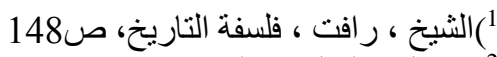

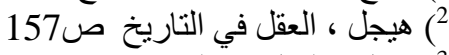

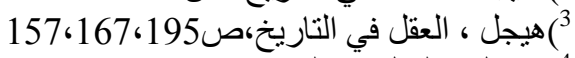

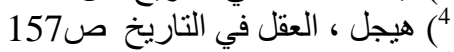

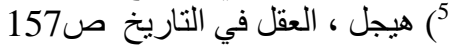

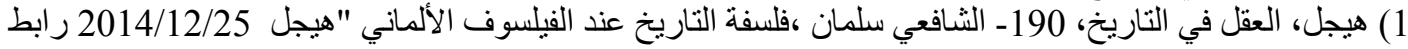
الموضوع: https://www.alukah.net/culture/0/80282/\#ixzz6iKSozDas194

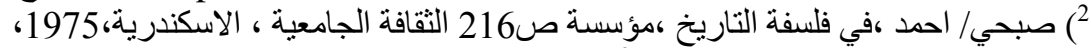

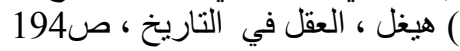




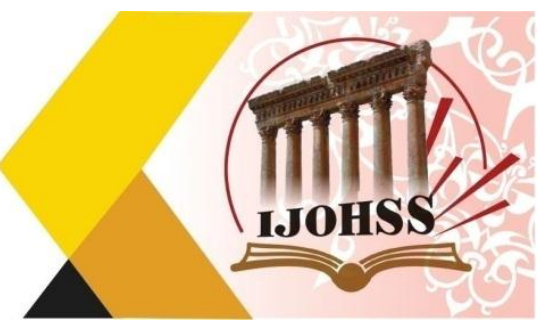

3-مرحلة المر اهقة: التي تمنلها اليونان.

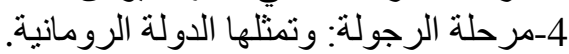

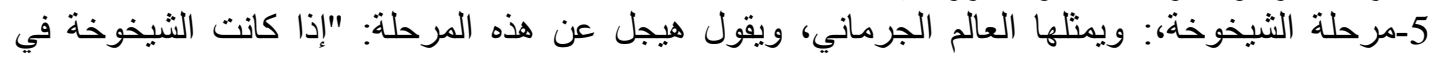

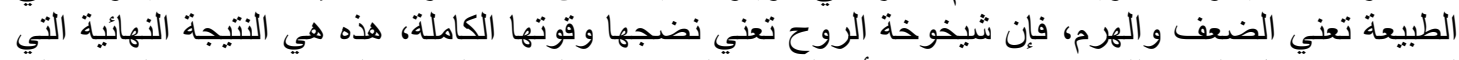

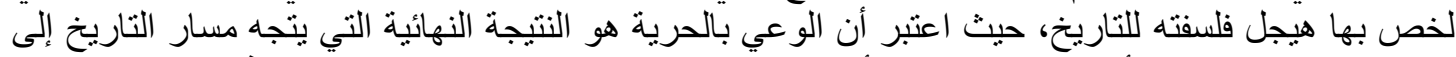

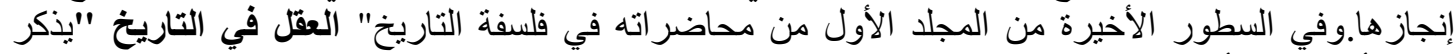

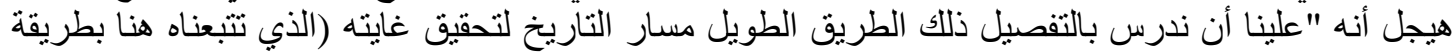

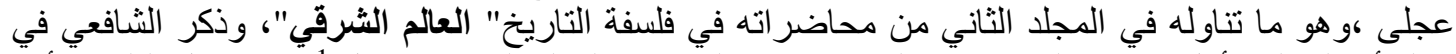

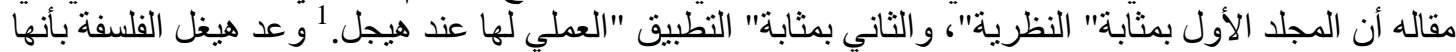

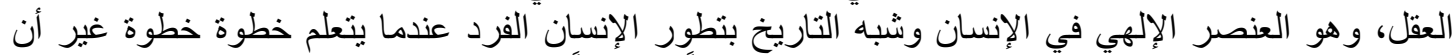

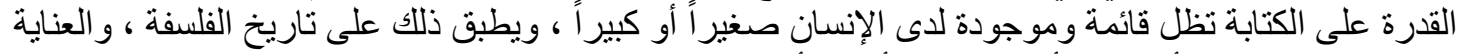

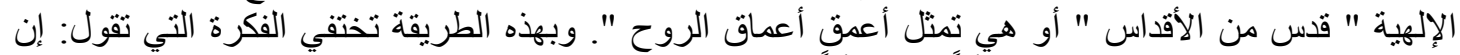

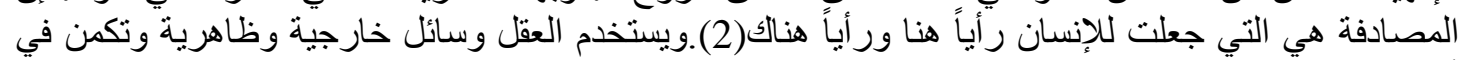

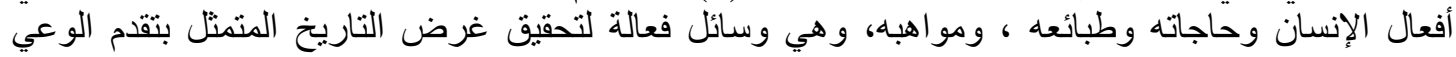

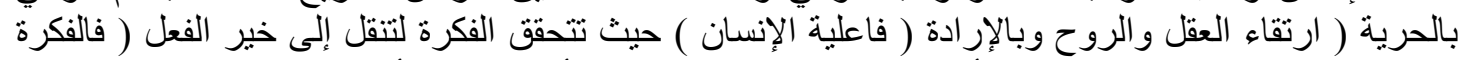

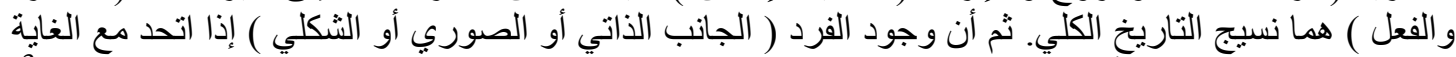

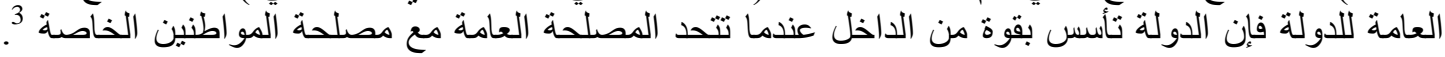

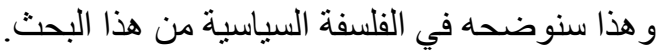

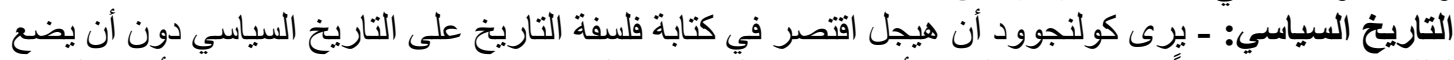

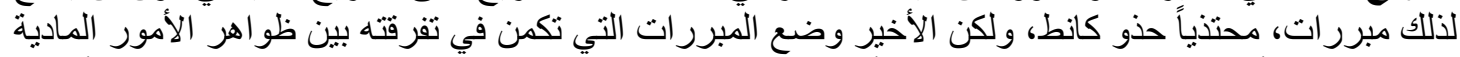

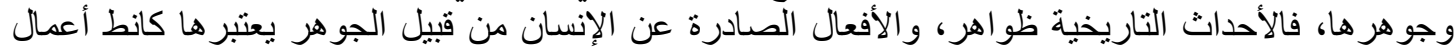

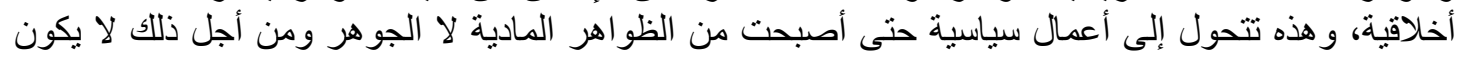

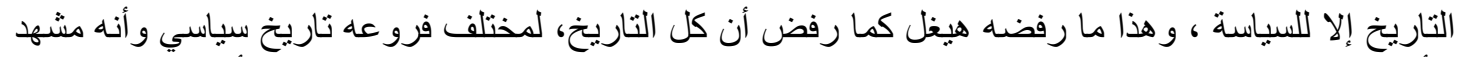

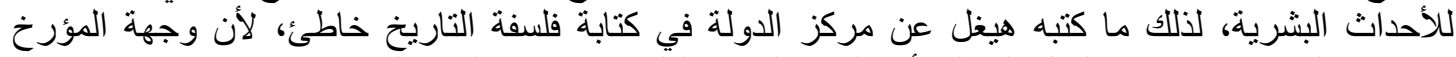

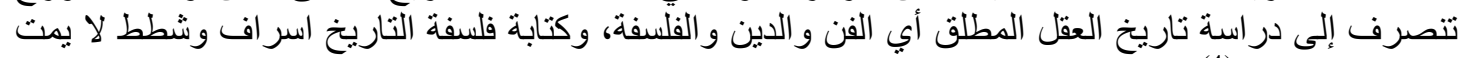

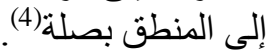

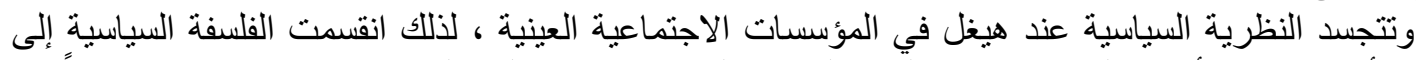

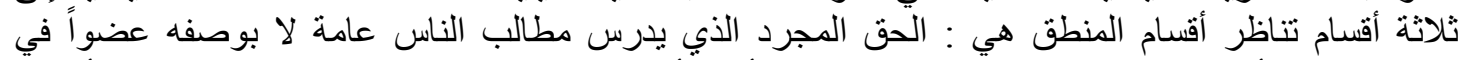

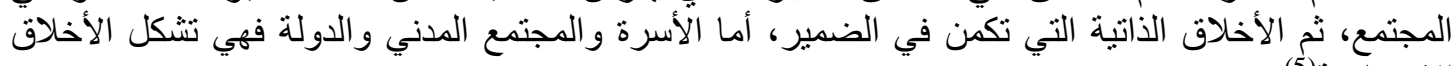

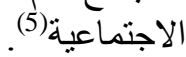

والأسرة هي الجوهر المباشرٍ للروح ، وفيها يمتلك المرء و وعياً ذاتياً بفرديته داخل هذه الوحدة التي هي الماهية

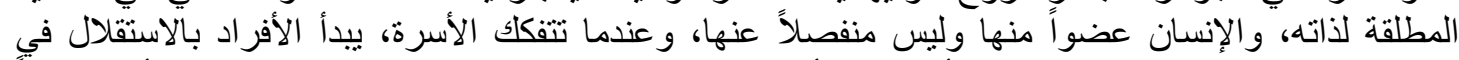

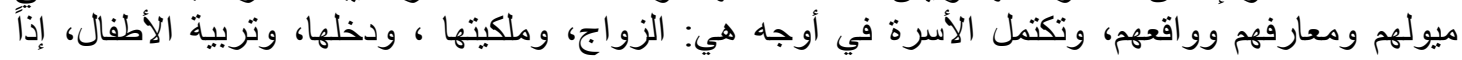

1) الثافعي سلمان ،فلسفة التاريخ عند الفيلسوف الألماني "هيجل 2014/12/25 رابط الموضوع: https://www.alukah.net/culture/0/80282/\#ixzz6iKSozDas 2) هيجل، محاضر ات هيغل في تاريخ الفلسفة، المكتبة الهيغلية، ترجمة امام عبدالفتاح ، مكتبة مدبولي، القاهرة ، 1997 ص .234-232

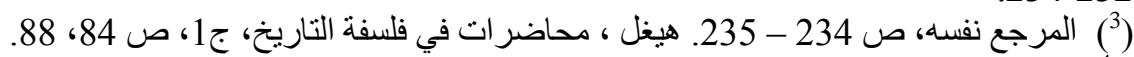
( ) (5) (إمام، أصول فلسفة ، الحق، ج2، صن صن 388 - 389. 
International Journal on Humanities and Social Sciences

website:www.ijohss.com

Email:editor@ijohss.com

ISSN: $2415-4822$

العدد (29) (

Volume (29) January 2022

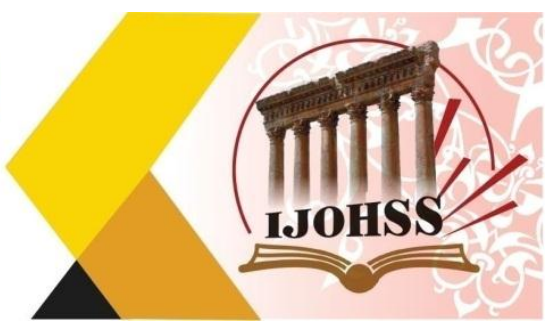

الأسرة هي الكلي من حيث الر ابطة والغاية، بل قيمة كل عضو مستمد من هذه الكلية ويشكل تفكلك الأسرة الذرات

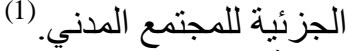
الدولة:ـ الدولة عند هيجل فهي فرد يشمل الكلي العيني، لأنه بر عى مصالح الجزئي و التاريخ لا يبدأ إلا بظهور

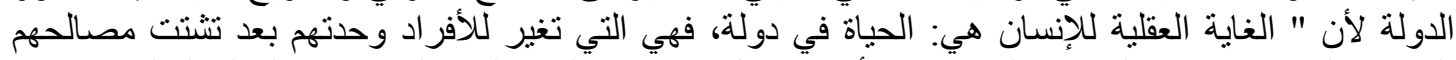

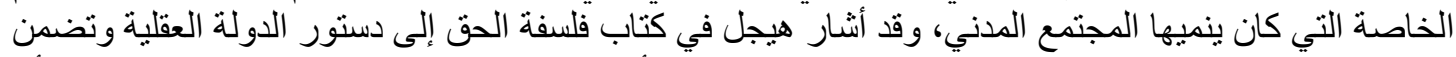

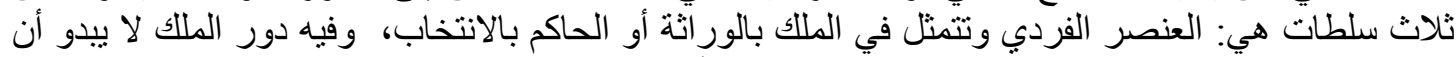

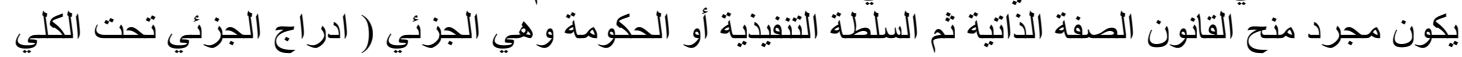

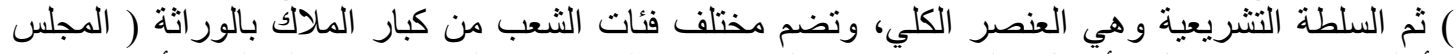

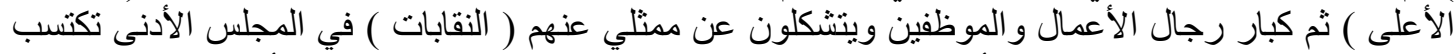

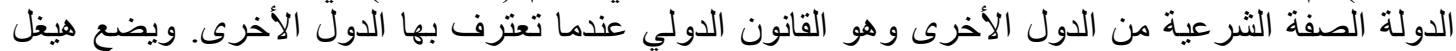

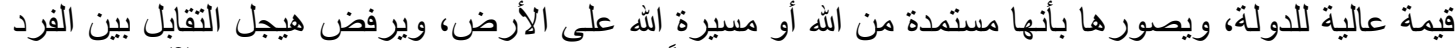

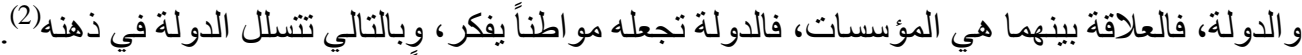

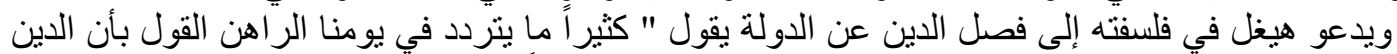

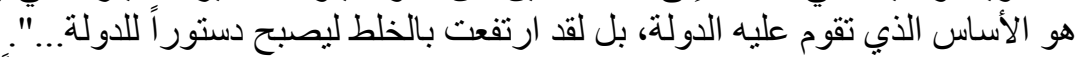

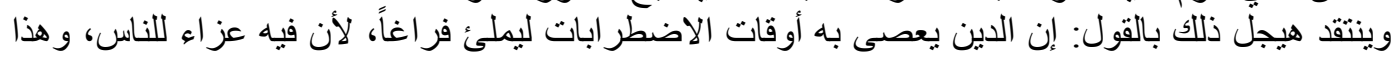

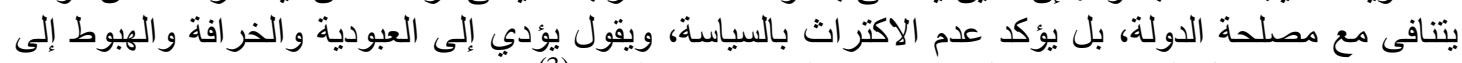

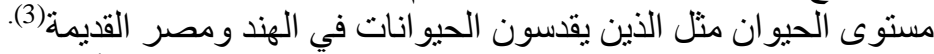

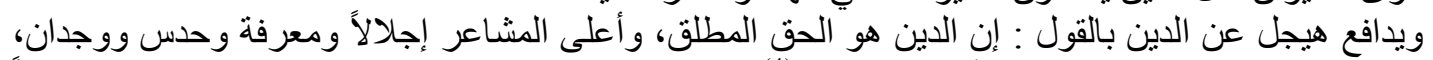

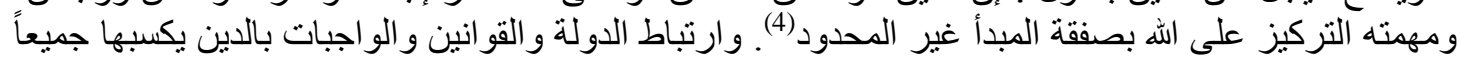

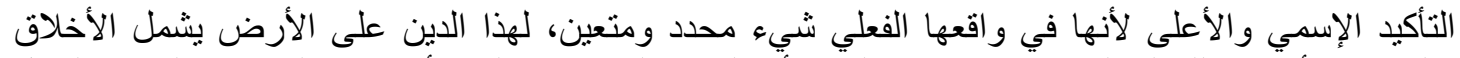

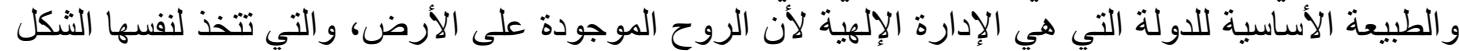

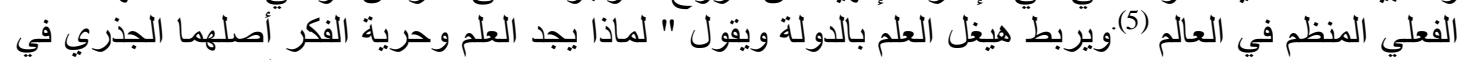

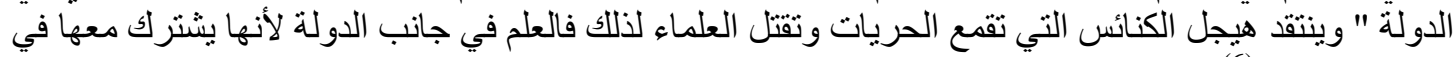
عنصر الصورة: (6).

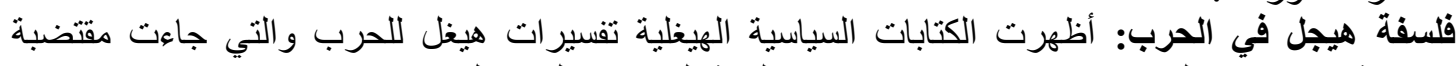

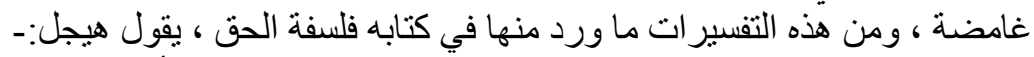

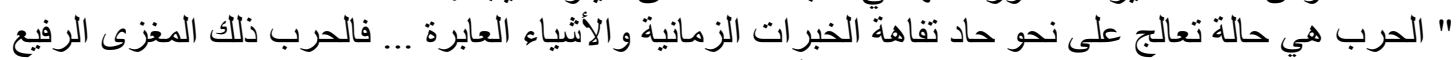

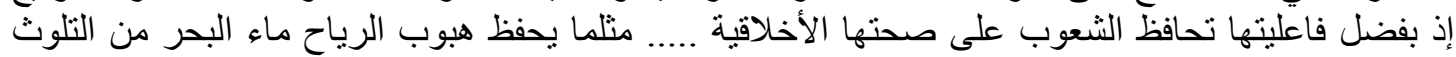

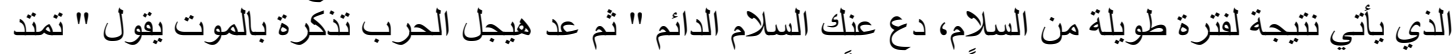

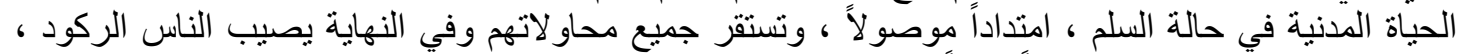

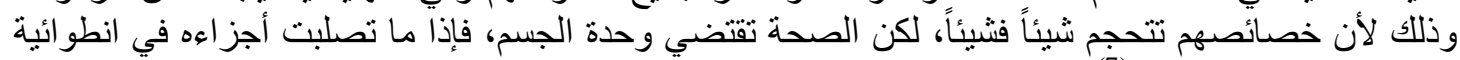

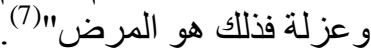

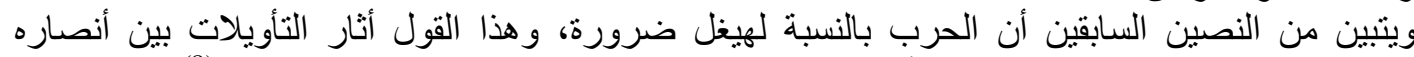
وخصومه: فالفريق المعارض للحرب قال أن هيغل داعية للنازية و القومية المتعصبة و الدكتاتورية (8).

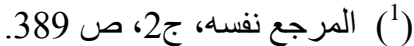

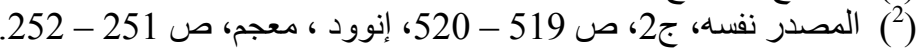

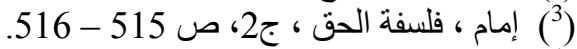

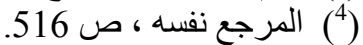

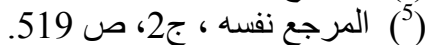

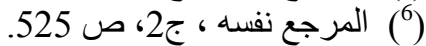

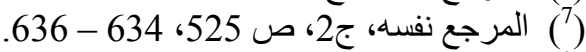

$$
\begin{aligned}
& \text { ( ) المرجع نفسه ، ج2، صع صن } 524 .
\end{aligned}
$$




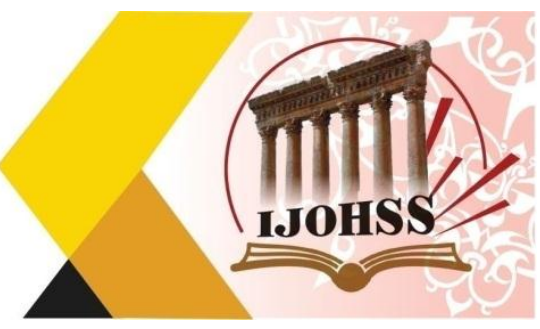

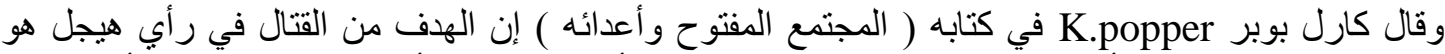

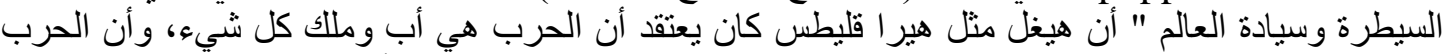

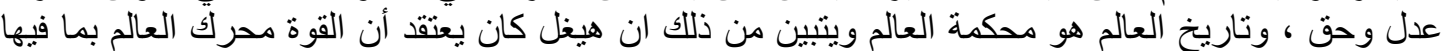

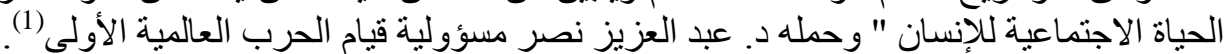

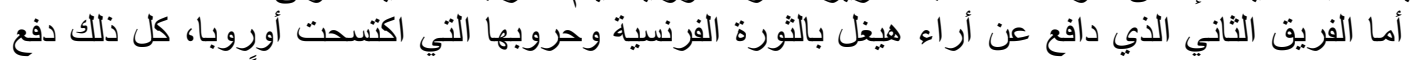

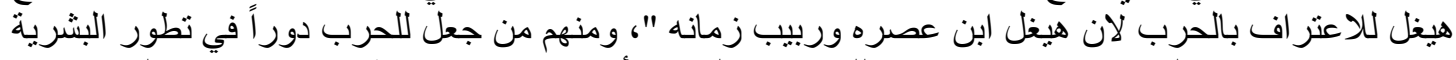

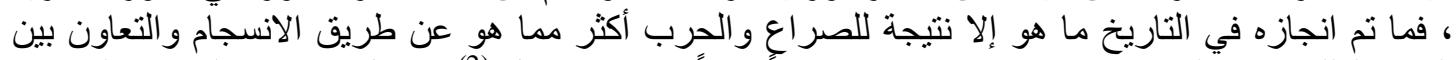

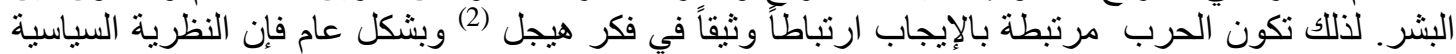

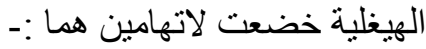

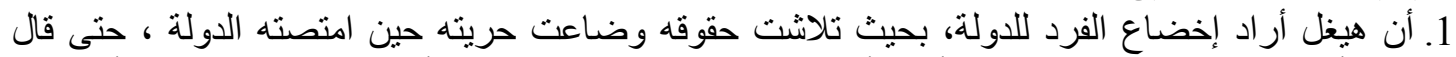

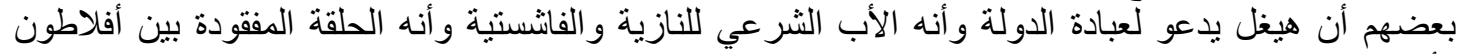

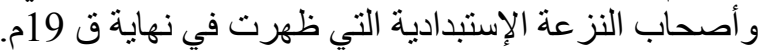

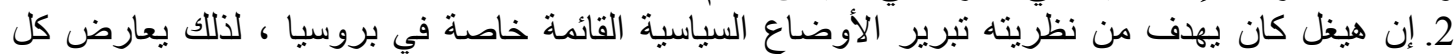

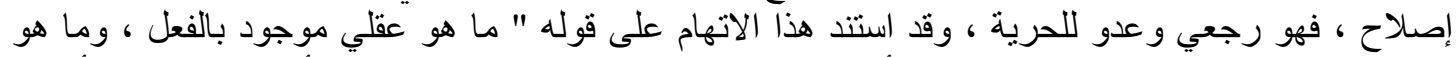

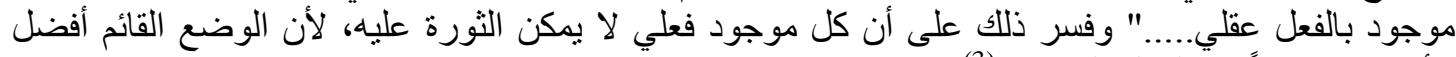
الأوضاع متمثلاً في الدولة البروسية(3).

المبحث الرابع : فلسفة هيغل بين النقد والتقدير

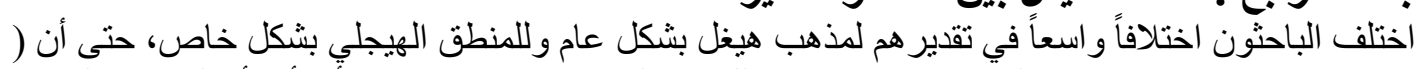

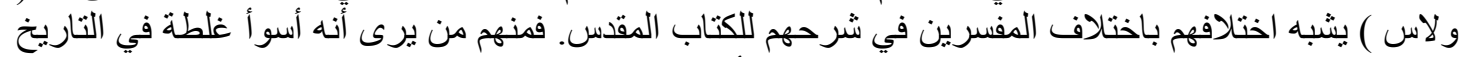

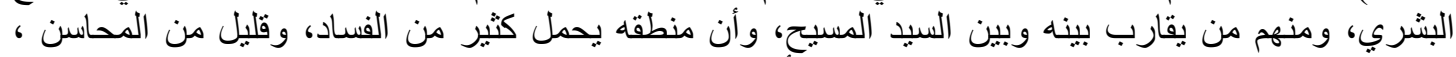

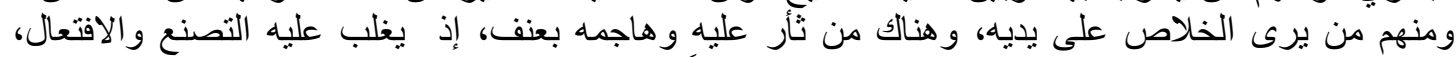

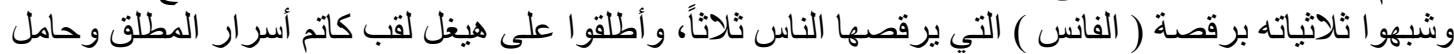

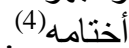

وبدأت من الهيغلية فلسفات حديثة في أواخر القرن م19 وأو وأوائل القرن العشرين كالماركسية والبرجماتية

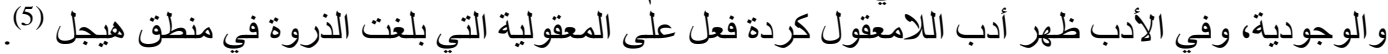

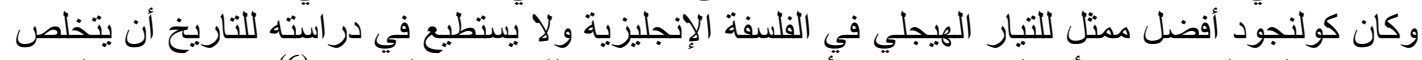

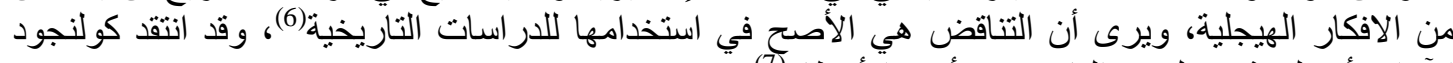

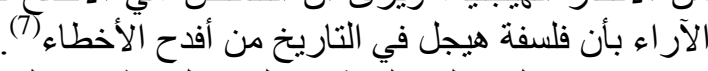

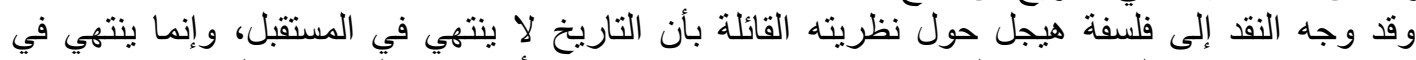

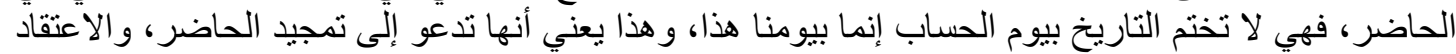

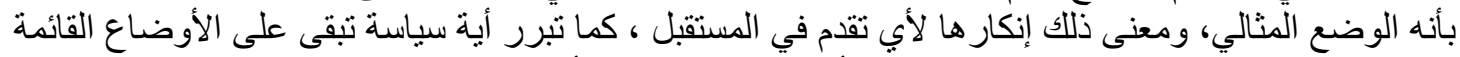

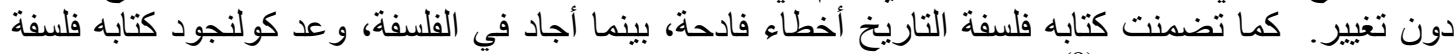

$$
\text { التاريخ ضرب من الإسر اف(8). }
$$

K.popper, The open society and its Enemies, vo p35( $\left.{ }^{1}\right)$

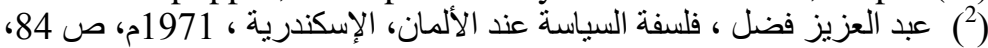

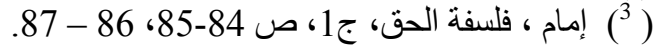

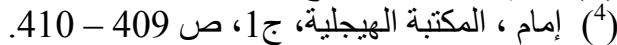

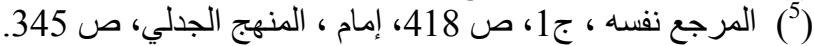

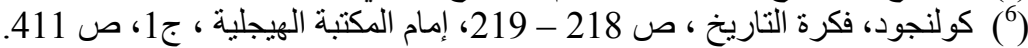

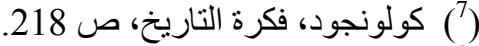

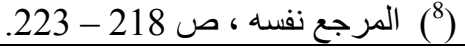




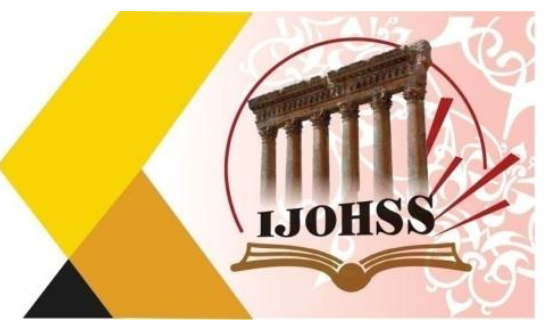

ومما يلفت الى فلسفة هيجل في التاريخ ، انها افتقرت إلى المادة التجريبية والحقيقة الموضو عية سواء في

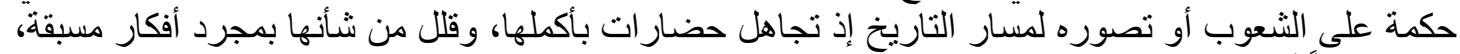

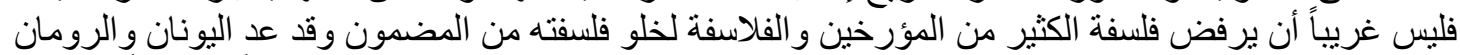

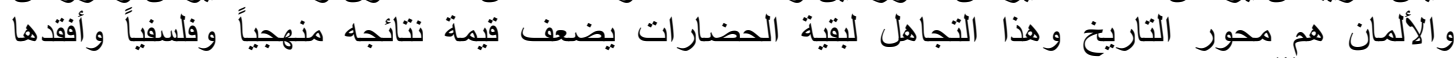

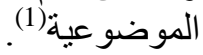

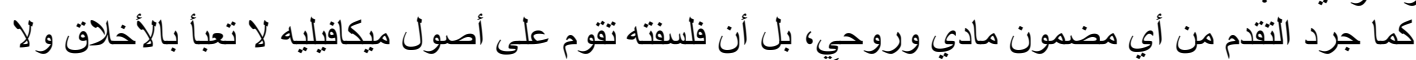

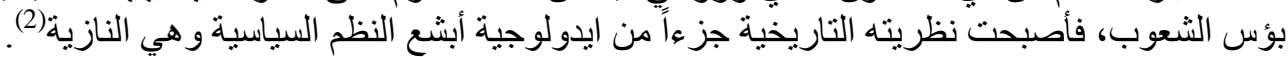

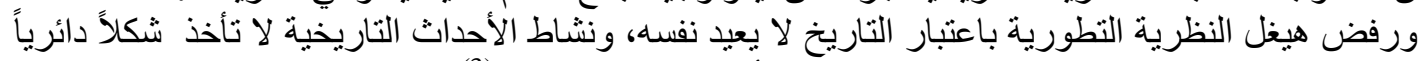

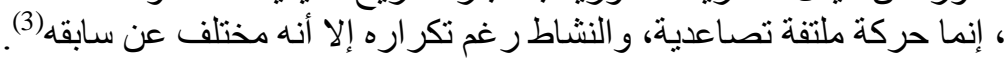

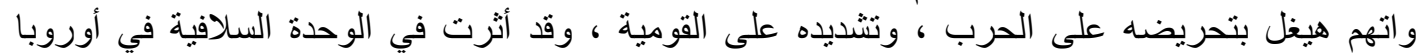

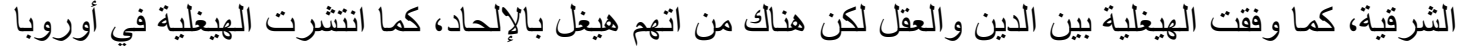

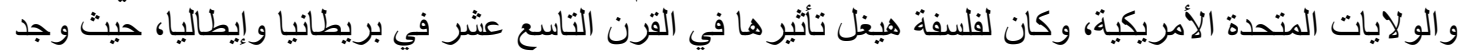

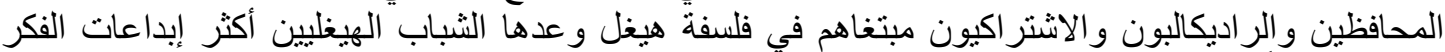
الإنساني تقدماً حتى الآن (4).

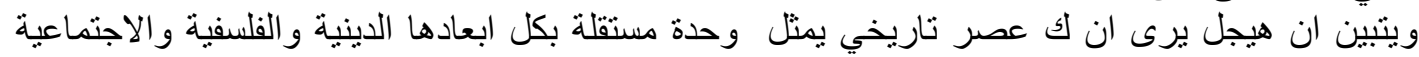

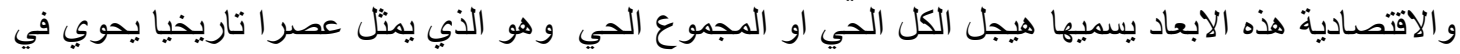

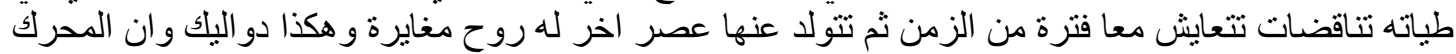

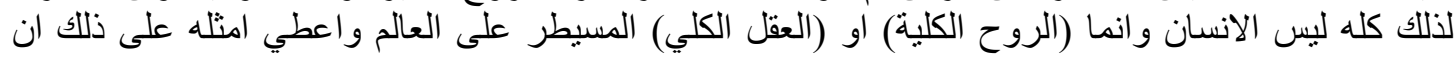

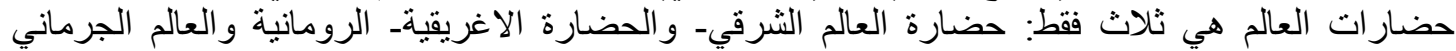

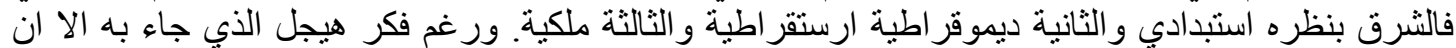

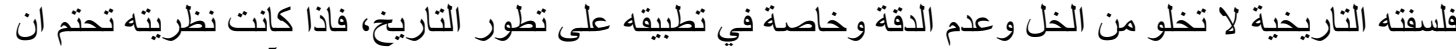

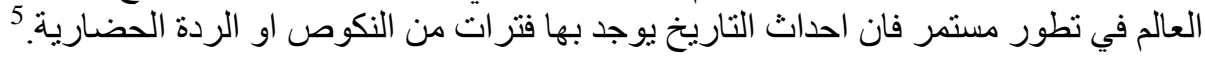

رفض هيخل النظرية التطورية باعنبار التاريخ لا بعيد نفسه، ونشاط الأحداث التاريخية لا تأخذ شكلاً دائرياً ،

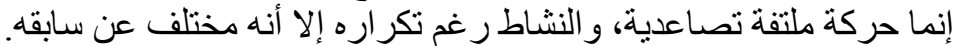

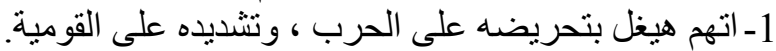

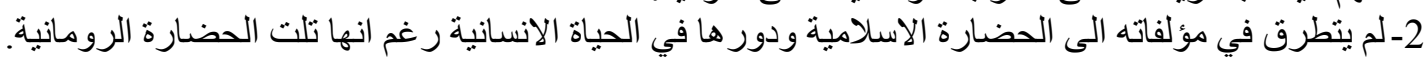

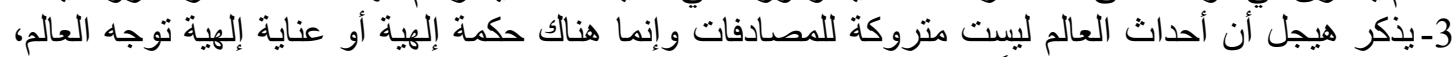
وبالتالي فإن كل ما يحدث للعالم طبقاً الخطة إلهية.

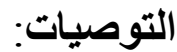
ـ اجر اء دراسات واطروحات ناريخية عميقة حول فلسفة هيجل التاريخية.

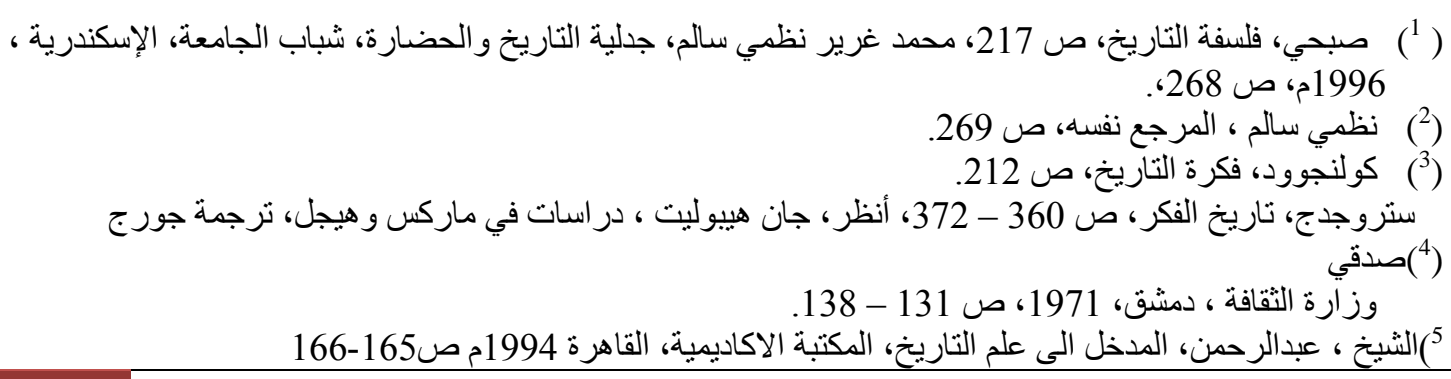




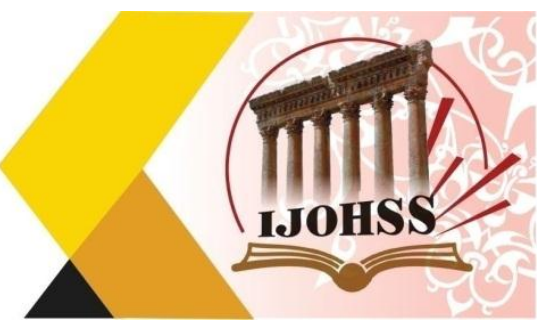

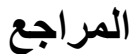

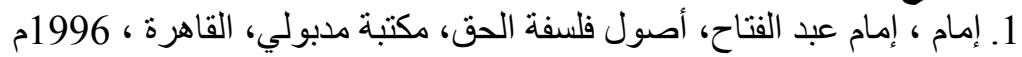

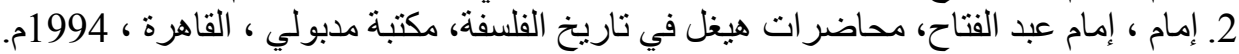

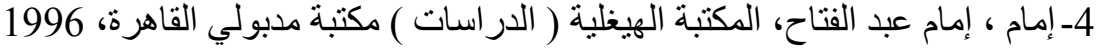

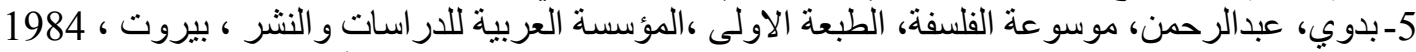
6- الربيعي، اسماعيل نوري، فلسفة التاريخ ( منطق الكثف التاريخي، الطبعة الأولى مكتبة الحامد ، عمان ،

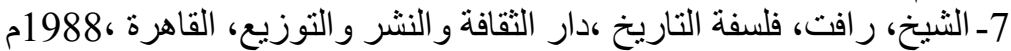

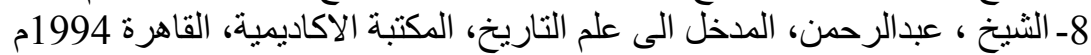

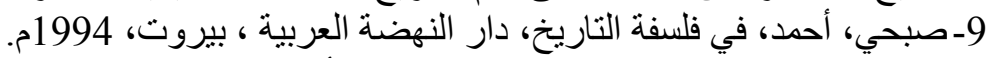

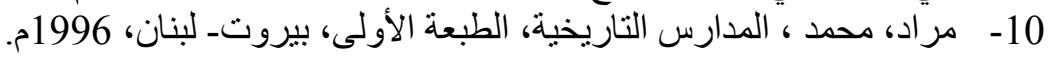

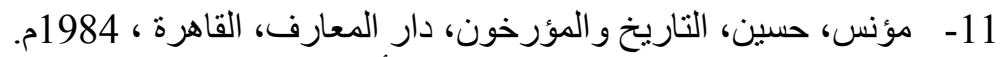

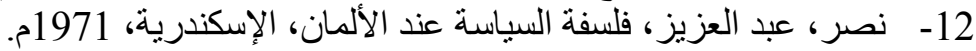

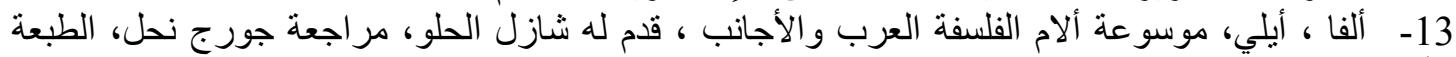

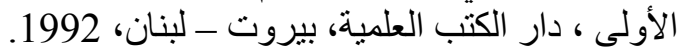

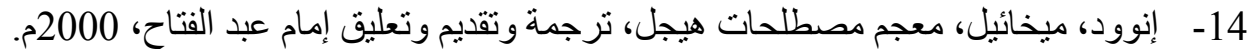

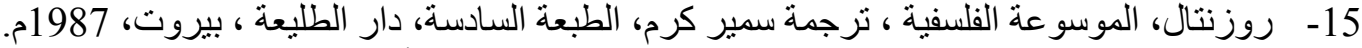

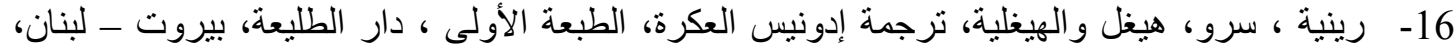
1993م.

17- ستومبرج، رونالد، تاريخ الفكر الأوروبي الحديث، ( 1601 - 1977م) ، نرجمة أحمد الثنيباني، الطبعة

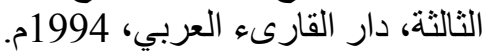
18- ستيس، ولتر ، فلسفة هيجل، نرجمة إمام عبد الفتاح، تقديم زكي نجيب محمود، دار الثقافة ، القاهرة ، 1980م. 19- كولنجوود، موج، فكرة التاريخ ، ترجمة محمد بكير خليل، مر اجعة محمد عبد الواحد خلاف، لجنة التأليف

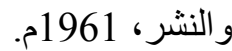
20- غديفوريان، ب، تان، الفلسفة وفلسفة التاريخ، ترجمة هيثم طه، مر اجعة رضوان القضماني، دار الفار ابي،

22- K.popper,The open society and its Enemiens, vol 1

$$
\text { 21 - هيغل ، محاضر ات في فلسفة التاريخ. }
$$

23- The New Encyclopaedia Britann ica, Hegel and Hegelianism, vol, 20

24- The Ency clopedia of philosophy, Hegel, vol 3

25- الثنافعي سلمان ،فلسفة التاريخ عند الفيلسوف الألماني "هيجل 2014/12/25 : بط الموضوع: https://www.alukah.net/culture/0/80282/\#ixzz6iKSozDas 